\title{
Migraine treatment recommendations developed by an Expert Group of the Polish Headache Society, the Headache Section of the Polish Neurological Society, and the Polish Pain Society
}

\author{
Adam Stępień ${ }^{1}$, Wojciech Kozubski ${ }^{2}$, Jacek J. Rożniecki ${ }^{3}$, Izabela Domitrz ${ }^{4}$ \\ ${ }^{1}$ Department of Neurology, Military Institute of Medicine in Warsaw, Warsaw, Poland \\ ${ }^{2}$ Department of Neurology, Charles Marcinkowski University of Medical Sciences, Poznan, Poland \\ ${ }^{3}$ Medical University of Lodz, Department of Neurology, Stroke and Neurorehabilitation, Lodz, Poland \\ ${ }^{4}$ Department of Neurology, Medical Faculty, Medical University of Warsaw, Warsaw, Poland
}

Key words: recommendations, guidelines, migraine, headaches, PTBG/PHS

(Neurol Neurochir Pol 2021; 55 (1): 33-51)

\section{Introduction}

Guidelines on the treatment of migraine developed by the European Federation of Neurological Societies (EFNS) were published in 2009 and then implemented by the European Academy of Neurology (EAN) [1]. In 2016, the American Headache Society (AHS) guidelines were released [2]. In Poland, the most recent studies concerning the management of migraine were published in 2011 and 2019 [3, 4].

The following recommendations are based on the aforementioned guidelines in relation to Polish conditions and therapeutic options in accordance with the principles of evidence-based medicine, good clinical practice, and the knowledge and experience of an Expert Group of the Polish Headache Society, the Headache Section of the Polish Neurological Society, and the Polish Pain Society. In the Groups report, the published opinions of global experts in migraine treatment are taken into consideration [5-7].

\section{Definition}

Migraine is a chronic, genetically determined disease characterised by the occurrence of headache attacks that are mainly located in one site of the head and are aggravated by physical activity. These headaches are accompanied by autonomic symptoms such as nausea and (sometimes) vomiting, as well as photophobia and phonophobia, which - if left untreated - can last for at least four hours. Migraine is a lifelong condition occurring with variable frequency among the victims. Between headache episodes, patients show constant readiness for the development of an attack.

\section{Diagnosis}

Migraine is more common in adult women (approximately $15-18 \%$ of the population) than in adult men $(6-8 \%$ of the population) $[8,9]$. However, $2.5 \%$ of women and $7.4 \%$ of men over the age of 65 suffer from migraine [10]. Migraine attacks can occur in childhood, but the onset of the disease is most commonly observed in the second and third decades of life. Before puberty, migraine occurs with equal frequency in boys and girls, with a prevalence of around 4\% [11]. An aura precedes the migraine attack in some patients (with symptoms occurring within 60 minutes before pain begins). A scotoma and flashes of light in the field of vision or other visual disturbances are the most common forms of aura, occurring in $90 \%$ of cases. In $77 \%$ of patients, prodromal symptoms occur, with an onset ranging from two to 48 hours before the aura and the migraine attack; the most frequent of these symptoms is yawning (34\%) [12].

The transformation of migraine from episodic to chronic or daily headaches is observed over a period of time in approximately $5-10 \%$ of patients. Unlike episodic migraine, chronic migraine is a disorder defined as headaches occurring at least

Address for correspondence: Jacek J. Rożniecki, Dept. of Neurology, Stroke and Neurorehabilitation, Medical University of Lodz, 22 Kopcinskiego Str., 90-153 Lodz, Poland, e-mail: jacek.rozniecki@umed.lodz.pl 
15 days each month, of which at least eight days of headache fulfill the criteria for migraine with or without aura, and/or either triptan or ergotamine relieves the pain, for at least three consecutive months. It is worth mentioning that the criteria for migraine attack are also met when the pain subsides after treatment with triptan or ergotamine. The diagnostic criteria for chronic migraine are based on the type of headache that previously fulfilled the criteria for episodic migraine with or without aura.

Migraine belongs to a group of primary headaches (i.e. there is no defined underlying pathological process). Physical examination does not reveal any abnormality in patients with migraine. There is some evidence to suggest that pain pathways in the central nervous system are activated during a migraine attack, especially through activation of the functional

system, including the first branch of the trigeminal nerve, anatomical structures of the brainstem, and the cerebral and meningeal vessels. Neuroimaging studies using functional magnetic resonance imaging in patients with this type of headache show primary activation of the aforementioned brain/ head structures, as well as the hypothalamus and thalamus. The raphe nuclei, locus coeruleus, and periaqueductal grey in the brainstem are thought to be primarily activated [13-15].

The causes of headache attacks remain unknown, but both endogenous and exogenous factors can trigger attacks [16].

When diagnosing migraine on the basis of a case history, the number of migraine days, the number of headache days, and the duration of pain must all be taken into account. Moreover, the number of days when using analgesics (for each drug group separately or together) should be assessed to confirm, or rule out, a medication-overuse headache, frequently associated with chronic migraine. Laboratory studies do not reveal any abnormalities in patients with migraine, and therefore ought to be ordered only in certain cases, mainly to exclude symptomatic headache. Migraine is one of the main diseases with a significantly negative impact on a patient's life by limiting the ability to work or to study, as well as impairing social functioning [17]. A major European study estimated that the mean annual cost of migraine was $€ 1,222$ per person [18], with indirect costs accounting for more than $93 \%$ of total costs borne by the healthcare system. The situation varies between countries. Annual indirect costs related to absenteeism and reduced productivity were $€ 475$ for men and $€ 435$ for women. The diagnosis of migraine is insufficient; hence, many patients remain without adequate treatment. Only one-third of individuals affected by migraine remain under medical care $[19,20]$.

\section{Diagnostic criteria for migraine}

The diagnostic criteria for migraine, first published in 1988, were modified in 2004 and 2013 [21, 22]. The latest version, ICHD-3 (International Classification of Headache Disorders, 3rd edition), was released in 2018 [23]. ICHD-3 distinguishes several types of migraine, but there are two major types of the disease: firstly, migraine without aura (this is the most common, afflicting $85-90 \%$ of patients) and secondly migraine with aura (often described as classic migraine, afflicting $10-15 \%$ of patients) [24]. Both types can be divided into an episodic and a chronic form.

There are five phases of a migraine attack, although not all of them are experienced in every attack: the prodrome, aura, pain, resolution, and postdrome [25].

\section{Episodic migraine}

According to the ICHD-3 criteria, migraine attacks last 4-72 hours. However, this does not include the prodrome and postdrome phases. In clinical practice, the duration of attacks is slightly shorter or longer in nearly one third of patients. Some patients experience only the pain phase, while other phases do not occur at all, or can be mild in their intensity. Migraine attacks are characterised by individual biological rhythm. Nearly $75 \%$ of patients experience fewer than four attacks per month [26]. Aura usually involves visual disturbances such as flashing lights, and can last from just a few minutes up to a maximum of 60 minutes. In those aged under 18 , migraine attacks can last 2-72 hours and headaches can be bilateral. Depending on the frequency of attacks, episodic migraine can be divided into low-frequency migraine (up to eight headache days per month) or high-frequency migraine (9-14 headache days per month). The episodic migraine category includes criteria for pure menstrual migraine and menstrually-related migraine. The diagnostic criteria for these types of migraine are discussed in a later section. The difference between pure menstrual migraine and menstrually-related migraine is associated with the occurrence of attacks: in the case of pure menstrual migraine, attacks occur only during menstruation. An accurate diagnosis determines differing pharmacological approaches. The diagnostic criteria for episodic migraine with and without aura are set out in Tables 1 and 2.

Table 1. Criteria for migraine without aura

A. At least five headache attacks fulfilling criteria B-D

B. Headache attacks lasting 4-72 hours (untreated or unsuccessfully treated)

C. Headache has at least two of the following four characteristics:

1. Is unilateral

2. Is pulsating

3. Intensity is moderate or severe

4. Is aggravated by, or causes avoidance of, routine physical activity (e.g. walking or climbing stairs)

D. At least one of the following symptoms occurs during headache:

1. Nausea and/or vomiting

2. Photophobia and phonophobia

E. Disorders are not better accounted for by another ICHD-3 diagnosis

ICHD-3 - International Classification of Headache Disorders, 3rd edition 
Table 2. Criteria for migraine with aura

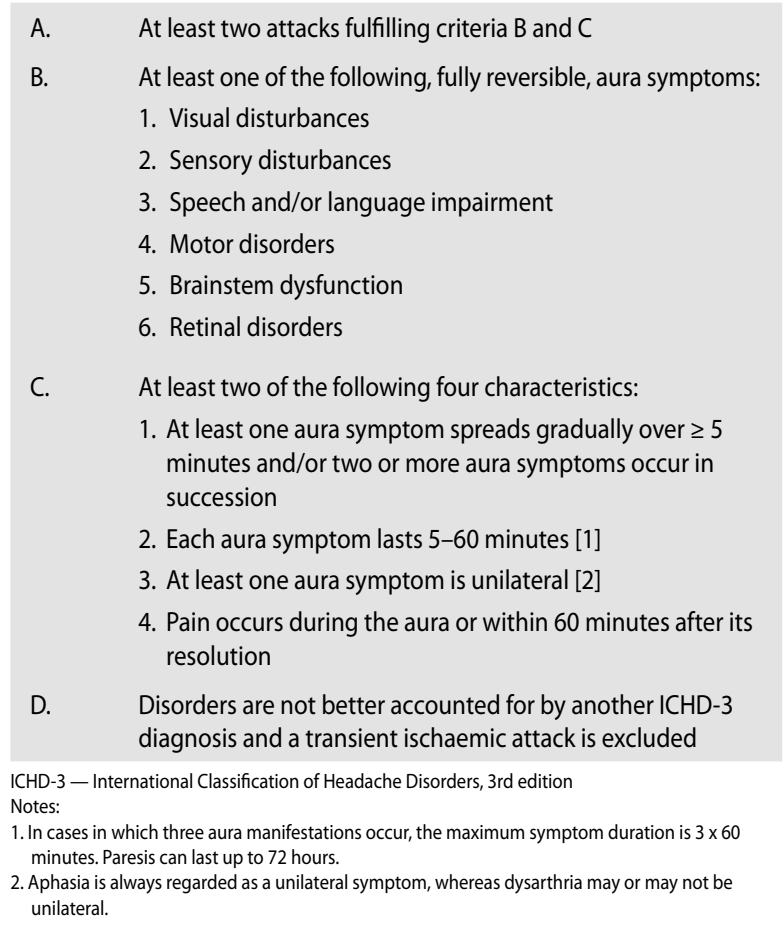

\section{Migraine without aura}

Description: Recurrent headaches manifesting in attacks lasting 4-72 hours. Typical characteristics of the headache include unilateral location (at least at the beginning of the attack), pulsating quality, moderate or severe intensity, aggravation by routine physical activity, nausea/vomiting and/ or photophobia and phonophobia.

\section{Migraine with aura}

Description: Recurrent attacks of fully reversible, unilateral visual disturbances, unilateral sensory disturbances, or other unilateral central nervous system disorders. The attacks usually develop gradually, last a few minutes, and are followed by headache and other migraine symptoms.

\section{Treatment of episodic migraine}

Migraine treatment aims to abort an acute attack (known as acute treatment) and, in the case of patients with frequent attacks, to protect the patient from new attacks. Patients with migraine should be monitored for the frequency of migraine attacks and other headaches to identify as soon as possible the risk of transformation from episodic to chronic migraine, as well as to administer preventive treatment early.

\section{Aims of acute treatment of migraine}

- Resolution of the migraine attack as quickly as possible, preferably within two hours
Table 3. Recommendations for the acute treatment of migraine

Principles of migraine attack treatment
Pharmacotherapy should be started immediately after the onset of
the attack
Medications should be used in adequate doses
First-line treatment for severe and moderate-to-severe attacks is the
administration of triptans (triptan or ergotamine therapies should be
started after the resolution of aura)
Mild and moderate attacks can be treated with NSAIDs, preferably in
effervescent form
Oral agents should be avoided when vomiting occurs
Patients with severe migraine attacks should be provided with an
additional analgesic (in addition to a triptan or ergotamine)
During an attack, the patient should not take higher doses than the
maximum prescribed dose of one medication
Pharmacotherapy should be limited to two days per week and to nine
days per month
Adverse drug effects should be monitored
Treatment efficacy should be assessed after two attacks treated with
the same medication
NSAIDs - non-steroidal anti-inflammatory drugs

- Reduction in pain intensity from severe or moderate to mild or no pain as quickly as possible, preferably within two hours

- Establishing effective treatment for subsequent migraine attacks

- Preventing migraine recurrence within 24 hours

\section{Additional aims}

- Minimising patient disability during the migraine attack

- Avoiding adverse effects

- Avoiding overuse of 'as needed' (pro re nata, PRN) analgesics

- Reduction in the number of migraine attacks requiring medical intervention

Early treatment of a migraine attack is more effective than delayed treatment: it shortensthe duration of the migraine and prevents recurrence $[1,2]$. Recommendations for the acute treatment of migraine are set out in Table 3.

Treatment should be based on the severity of migraine symptoms, assessed using a four-grade scale:

$$
\begin{aligned}
& 1 \text { - no pain } \\
& 2 \text { - mild pain } \\
& 3 \text { - moderate pain } \\
& 4 \text { - severe pain }
\end{aligned}
$$

Assessment of migraine attack severity is set out in Table 4.

NSAIDs can be used to treat attacks of mild-to-moderate pain. The medication is individually chosen, and it is important to take it as early as possible and in a sufficiently high dose [27].

Sumatriptan is the 'gold standard' for the treatment of severe attacks. Ergotamine and its derivatives show less efficacy than triptans. Being non-selective, although specific, ergotamine causes more side effects (mainly cardiovascular) and is consequently being used with decreasing frequency [28]. 
Table 4. Assessment of migraine attack severity

$\begin{array}{ll}\text { Mild attacks } & \begin{array}{l}\text { Patient maintains ability to perform daily activities, } \\ \text { although these may be limited compared to period } \\ \text { without an attack }\end{array} \\ \begin{array}{l}\text { Moderate-to- } \\ \text {-severe attacks }\end{array} & \begin{array}{l}\text { Patient's ability to work is significantly reduced } \\ \text { Severe attacks }\end{array} \\ & \begin{array}{l}\text { Patient stays in bed in a dark and quiet room, away } \\ \text { from any stimuli }\end{array}\end{array}$

\section{Simple analgesics and NSAIDs}

Acetaminophen and NSAIDs are recommended for aborting migraine attacks of mild intensity. In several randomised, placebo-controlled trials, the following NSAIDs demonstrated efficacy: acetylsalicylic acid (ASA) up to $500-1,000 \mathrm{mg}$, ibuprofen $200-800 \mathrm{mg}$, and diclofenac $50-100 \mathrm{mg}$, as well as simple analgesic acetaminophen at a dose of 500-1,000 $\mathrm{mg}$ [29-32]. In clinical practice, medications containing a combination of acetaminophen, ASA, and caffeine are used. Caffeine, like the other two compounds, exhibits analgesic properties that together are better than placebo under specific conditions [33-35]. A fixed combination of the aforementioned compounds in a 1.0:0.8:0.2 ratio is recommended, with a tablet containing not less than $50 \mathrm{mg}$ of caffeine. The efficacy of this combination is statistically superior to that of a placebo and to that of a single component alone [36]. A combination of acetaminophen $500 \mathrm{mg}$, ASA $500 \mathrm{mg}$, and caffeine $130 \mathrm{mg}$ seems to be more effective than sumatriptan $50 \mathrm{mg}$ in the treatment of migraine attacks [37]. Different NSAIDs show comparable clinical efficacy, which can vary between patients. Metamizole sodium is also widely used. Randomised, double-blind trials have demonstrated high efficacy of metamizole sodium in aborting migraine attacks $[38,39]$. The recommended first-line drugs for the acute treatment of migraine are set out in Table 5 .

The effervescent form of ASA is recommended for patients with acute nausea or vomiting, as a single dose of $1,000 \mathrm{mg}$ in combination with an antiemetic drug, e.g. metoclopramide $10 \mathrm{mg}$. When oral administration is not possible, lysine acetylsalicylate can be administered intravenously. The benefit of such therapy has been confirmed in numerous open-label and double-blind trials $[40,41]$. Benzodiazepines and tramadol are not recommended in patients with migraine. Antiemetics (oral or intravenous metoclopramide $20 \mathrm{mg}$ ) are recommended for patients with coexisting acute nausea or vomiting (Table 6) [42]. Studies have not confirmed that adding an antiemetic to the analgesic increases the efficacy of treatment. Metoclopramide may induce extrapyramidal side effects, and is therefore not recommended in children or elderly patients.

\section{Ergotamine and ergot alkaloids}

Ergotamine has long been considered the most effective drug for the acute treatment of migraine and, so far, remains
Table 5. Recommended first-line drugs and doses in the acute treatment of migraine attacks

\begin{tabular}{|c|c|c|}
\hline Substance & Dose & $\begin{array}{l}\text { Level of } \\
\text { recommendation }\end{array}$ \\
\hline \multirow[t]{2}{*}{ ASA } & $1,000 \mathrm{mg}$ (oral) & A \\
\hline & $1,000 \mathrm{mg}$ (intravenous) & $A$ \\
\hline Ibuprofen & 200-800 mg (oral) & A \\
\hline Naproxen & $500-1,000 \mathrm{mg}$ (oral) & A \\
\hline Diclofenac & 50-100 mg (oral/rectal) & A \\
\hline \multirow[t]{2}{*}{ Acetaminophen } & $1,000 \mathrm{mg}$ (oral) & A \\
\hline & $1,000 \mathrm{mg}$ (rectal) & A \\
\hline $\begin{array}{l}\text { ASA + para- } \\
\text { cetamol + } \\
\text { caffeine }\end{array}$ & $\begin{array}{c}250 \mathrm{mg}, 200-250 \mathrm{mg} \\
\text { and } 50 \mathrm{mg} \text { (oral) }\end{array}$ & A \\
\hline \multirow{2}{*}{$\begin{array}{l}\text { Metamizole } \\
\text { sodium }\end{array}$} & $1,000 \mathrm{mg}$ (oral) & B \\
\hline & $1,000 \mathrm{mg}$ (intravenous) & B \\
\hline Tolfenamic acid & 200 mg (oral) & B \\
\hline Ergotamine & $1-2 \mathrm{mg}$ (oral) & B \\
\hline Metamizole & $\begin{array}{c}1,000 \mathrm{mg} \text { (oral/intrave- } \\
\text { nous/rectal) }\end{array}$ & B \\
\hline Tolfenamic acid & 200-400 mg (oral) & B \\
\hline
\end{tabular}

Table 6. Recommended second-line anti-emetic drugs and doses in the acute treatment of migraine attacks

\begin{tabular}{|c|c|c|}
\hline Drug & Single dose & $\begin{array}{l}\text { Level of recom- } \\
\text { mendation }\end{array}$ \\
\hline \multicolumn{3}{|c|}{ Antiemetics/prokinetics } \\
\hline Metoclopramide & $\begin{array}{l}10-20 \text { mg orally; } 20 \\
\text { mg rectally; or } 10 \mathrm{mg} \\
\text { parenterally (intrave- } \\
\text { nously, intramuscular- } \\
\text { ly, or subcutaneously) }\end{array}$ & B \\
\hline Domperidone & $20-30 \mathrm{mg}$ orally & $B$ \\
\hline Prochlorperazine & 10 mg orally & B \\
\hline
\end{tabular}

a class $\mathrm{A} / \mathrm{B}$ drug. However, a broad range of side effects are associated with ergotamine because it can cause constriction of the peripheral and coronary vessels. Despite years of experience, only a few placebo-controlled clinical studies of the efficacy of ergot alkaloids for aborting migraine have been conducted. Medicines containing ergot can still be used, but triptans have proven to be more effective in comparative studies [43].

Therefore, using ergot derivatives to treat migraine is generally not recommended, and should be used only for specially selected patients. In some patients, ergot alkaloids reduce the recurrence of migraine. They are therefore currently recommended only for patients with very long-lasting, or frequently recurring, migraine attacks. Ergotamine tartrate administered orally and the suppository form of dihydroergotamine $2 \mathrm{mg}$ 
have proved effective. The daily dose should not exceed 2-4 mg, with a maximum dose per month of $16 \mathrm{mg}$. Use of the drug should be limited to 10 days per month.

Ergot-related side effects include nausea and vomiting, paresthesia of the extremities, and ergotism. Medicines containing ergot alkaloids are contraindicated in people with cardiovascular diseases, hypertension, Raynaud's disease, and kidney failure, as well as during pregnancy and breastfeeding. Over the years, various analyses have demonstrated that ergotamine slightly, but significantly, increases the risk of stroke [44]. Even small doses of ergot alkaloids can cause rebound headaches.

\section{Triptans (5-HT1B/1D agonists)}

The $5-\mathrm{HT} 1 \mathrm{~B} / 1 \mathrm{D}$ receptor agonists including sumatriptan, zolmitriptan, naratriptan, rizatriptan, almotriptan, eletriptan, and frovatriptan are a specific and selective class of drugs called triptans that are used in the treatment of migraine attacks.

Triptans are recommended in patients whose migraines respond poorly to NSAIDs or in whom NSAIDs are contraindicated. There are fewer side effects associated with triptans than with ergotamine, and triptans are more effective at aborting migraine attacks [45]. Differences between triptans arise from their pharmacokinetic properties, dosage form, routes of administration, onset of action (time to achieve full analgesic effect), half-life, bioavailability, metabolism, and route of elimination. The efficacy of triptans is determined by their action on the trigeminovascular system, with serotonin $5 \mathrm{HT} 1 \mathrm{~B} / \mathrm{D}$ receptor serving as the target, as well as their inhibition of nociceptive neurotransmission, mainly by targeting the 5HT1D receptor subtype. These drugs constrict cranial blood vessels by affecting the $5 \mathrm{HT} 1 \mathrm{~B}$ receptor, but do not disrupt blood flow.
A number of randomised, placebo-controlled clinical trials and numerous meta-analyses have confirmed the efficacy of triptans for the abortive treatment of migraine [46]. For sumatriptan and zolmitriptan, comparative studies with ASA and metoclopramide were carried out $[47,48]$. Another comparative study demonstrated that triptans were not, or were only slightly, more effective than ASA. Triptans appeared to be effective in approximately $60 \%$ of non-responders to NSAIDs [49]. Sumatriptan $6 \mathrm{mg}$ administered subcutaneously is more effective than ASA 1,000 mg administered i.v., but causes more side effects. According to comparative studies, medications containing ergotamine are less effective than sumatriptan and eletriptan $[50,51]$. Triptans are effective in every phase of a migraine attack. It is recommended that the adequate dose of drug be taken immediately after the beginning of the attack, when the pain is mild or moderate. This ensures quicker resolution and alleviation of pain and associated symptoms, as well as decreased frequency of recurrence [52]. Pain relief is defined as a reduction in the intensity of pain from severe to moderate or none after two hours. Use of these drugs is not recommended during migraine aura, and they do not prevent the development of headaches when administered during this phase [53]. Early intake of triptans has been shown to be more effective than delayed treatment [54]. However, a strategy of early treatment of migraine attacks can lead to more frequent use of triptans in particular patients. The use of triptans should be limited to a maximum of 10 days per month. All triptans can cause drug-induced headaches [55]. It is recommended that patients should control their triptan intake, and note the amount of the drug taken in a diary. If no effect is seen after the first dose of triptan, the dose can be repeated after at least two hours. Triptan doses, forms, and levels of evidence based on clinical trials are set out in Table 7. The efficacy of triptans according to meta-analyses of clinical trials is set out in Table 8 .

Table 7. Triptans, their dosage forms, doses, and levels of evidence based on clinical trials

\begin{tabular}{|c|c|c|c|}
\hline Substance & Dose & Level of evidence & Notes \\
\hline \multirow[t]{4}{*}{ Sumatriptan } & $25,50,100 \mathrm{mg}$ (oral) & A & Dose of $100 \mathrm{mg}$ considered to be the 'gold standard' \\
\hline & $25 \mathrm{mg}$ (rectal) & A & \\
\hline & $10,20 \mathrm{mg}$ (nasal spray) & A & \\
\hline & $6 \mathrm{mg}$ (subcutaneous) & A & \\
\hline \multirow[t]{2}{*}{ Zolmitriptan } & $2.5,5.0 \mathrm{mg}$ (oral) & A & \\
\hline & 2.5 and $5.0 \mathrm{mg}$ (nasal spray) & A & \\
\hline Naratriptan* & $2.5 \mathrm{mg}$ (oral) & A & Long-acting drug (>20 hours) \\
\hline Rizatriptan & $10 \mathrm{mg}$ (oral) & A & Orally disintegrating tablets; 5 mg when taking propranolol \\
\hline Almotriptan & $12.5 \mathrm{mg}$ (oral) & A & Has fewer side effects than sumatriptan \\
\hline Eletriptan & $20,40 \mathrm{mg}$ (oral) & A & Recommended dose of $80 \mathrm{mg}$, if $40 \mathrm{mg}$ dose inadequate \\
\hline Frovatriptan* & $2.5 \mathrm{mg}$ (oral) & A & Long-acting drug (>20 hours) \\
\hline
\end{tabular}


Table 8. Efficacy of triptans according to meta-analyses of clinical trials $[17,18]$

\begin{tabular}{|c|c|c|c|c|}
\hline Drug name/dose & $\begin{array}{l}\text { Pain reduction } \\
\text { after } \mathbf{2} \text { hours }\end{array}$ & $\begin{array}{l}\text { Headache relief } \\
\text { after } \mathbf{2} \text { hours }\end{array}$ & $\begin{array}{c}\text { Recurrence } \\
\text { (percentage } \\
\text { occurance) }\end{array}$ & $\begin{array}{c}\text { Number needed to treat } \\
\text { ( } 2 \text { hours after headache relief } \\
\text { vs placebo) }\end{array}$ \\
\hline Eletriptan 40 mg (oral) & $65 \%$ & $29 \%$ & $23 \%$ & 4.5 \\
\hline Eletriptan $80 \mathrm{mg}$ (oral) & $77 \%$ & $37 \%$ & $19 \%$ & $4.5(4.0$ to 5.1$)$ \\
\hline Naratriptan $2.5 \mathrm{mg}$ (oral) & $51 \%$ & $21-19 \%$ & $17-28 \%$ & 8.5 \\
\hline Rizatriptan 5 mg (oral) & $67 \%$ & $33 \%$ & $47 \%$ & 3.9 (3.3 to 4.7$)$ \\
\hline Rizatriptan $10 \mathrm{mg}$ oral & $80 \%$ & $45-48 \%$ & $30 \%$ & 3.1 \\
\hline Sumatriptan 6 mg (subcutaneouly) & $79 \%$ & $60 \%$ & $34-38 \%$ & 2.3 \\
\hline Sumatriptan 50 mg (oral) & $61 \%$ & $36 \%$ & $32 \%$ & 6.1 \\
\hline Sumatriptan 100 mg (oral) & $61 \%$ & $41 \%$ & $30 \%$ & 4.7 \\
\hline Sumatriptan 20 mg (nasal spray) & $78 \%$ & $30 \%$ & $32-34 \%$ & 4.7 \\
\hline Zolmitriptan 2.5 mg (oral) & $69 \%$ & $29 \%$ & $30 \%$ & 5.9 \\
\hline Zolmitriptan 5 mg (oral) & $70 \%$ & $38 \%$ & $30 \%$ & 4.6 \\
\hline
\end{tabular}

Table 9. Pharmacokinetic properties and bioavailability of (oral) triptans [61]

\begin{tabular}{|c|c|c|c|c|c|c|}
\hline Triptan & $\begin{array}{l}\text { Tmax } \\
\text { (hours) }\end{array}$ & $\begin{array}{c}\mathrm{T} 1 / 2 \\
\text { (hours) }\end{array}$ & $\begin{array}{l}C \max \\
(\mathrm{mg} / \mathrm{l})\end{array}$ & Bioavailability & $\begin{array}{l}\text { Lipophilicity } \\
(\log \mathrm{DpH}=7.4)\end{array}$ & CNS side effects \\
\hline Almotriptan & $1.5-2.0$ & 3 & 49,5 & 70 & -2.1 & -1.5 \\
\hline Eletriptan & $1.0-1.5$ & 4 & 246 & 50 & +0.5 & $2.6-14.6$ \\
\hline Frovatriptan & $2.0-3.0$ & 26 & $7.0 / 4.2^{*}$ & $24-30$ & -1.0 & 6.0 \\
\hline Naratriptan & $2.0-3.0$ & 6 & 12.6 & $74 / 63^{*}$ & -0.2 & 1.9 \\
\hline Rizatriptan & $1.0-1.5$ & 2 & 19.8 & $40-45$ & -0.7 & $6.1-9.4$ \\
\hline Sumatriptan & $2.0-3.0$ & 2 & 54 & 14 & -1.5 & $1.7-6.3$ \\
\hline Zolmitriptan & $1.5-2.0$ & 3 & 10 & $41-48$ & -1.0 & $9.9-11.5$ \\
\hline
\end{tabular}

All triptans can cause migraine recurrence within 24 hours after the first drug dose. Migraine recurrence is defined as a recurrent intensification of headache pain to severe within 24 hours after pain has been reduced to moderate or none [56]. Recurrent headaches occur in approximately $30 \%$ of patients treated with triptans. In the case of recurrence, another dose of triptans is as effective as the initial dose [57]. The combination of a triptan with a long-acting NSAID (e.g. naproxen $500-1,000 \mathrm{mg}$ ) is recommended for patients with frequent recurrence of attacks. Headache recurrence occurs more often in patients taking NSAIDs or triptans than in those treated with ergotamine. According to clinical trials, the incidence rate of side effects with triptans is similar to that with placebo. The most commonly observed side effects include nausea and dizziness, asthenia, and chest pain or tightness. After administration of triptans, myocardial infarction, stroke, and arrhythmia have been reported; however, the estimated incidence of these events is low -1 per $1,000,000$ patients. The risk of side effects is no higher than in healthy individuals from the general population [58].

Contraindications for the use of triptans include uncontrolled hypertension, coronary heart disease, Raynaud's syndrome, history of myocardial infarction or stroke, pregnancy, lactation, and acute liver or renal failure. There are some minor differences between triptans in terms of bioavailability, duration of action, and efficacy (Table 9). Resistance to treatment with one triptan is relatively stable [59]. Even if one triptan appears to be ineffective, another one can be effective in a particular patient. The most effective drug with the fastest onset of action for aborting migraine attacks is sumatriptan $6 \mathrm{mg}$, administered subcutaneously. Rizatriptan and eletriptan administered orally have a rapid onset of action (after about 30 minutes); oral sumatriptan, almotriptan, and zolmitriptan have a slower onset of action (after 45-60 minutes); whereas the onset of action with naratriptan and frovatriptan is 4-6 hours and up to 26 hours, respectively [60].

It is worth noting that the treatment of migraine and coexisting depression with concomitant use of triptans and SSRI/NSRI might be a risk of serotonin syndrome; however the potential risk of it is quite low, and thus patients should not be strongly advised to definitely stop triptans while on SSRI treatment [62].

A summary of selected drugs used to treat migraine attacks is set out in Table 10, and the guidelines for treatment of migraine attacks based on evidence-based medicine criteria are set out in Table 11. 
Table 10. Summary of selected drugs used to treat a migraine attack

\begin{tabular}{|c|c|c|}
\hline Drug name & $\begin{array}{l}\text { Maximum single } \\
\text { dose }\end{array}$ & $\begin{array}{l}\text { Class of recom- } \\
\text { mendation }\end{array}$ \\
\hline Paracetamol & 1,000 mg orally & $A$ \\
\hline ASA & 1,000 mg orally & $A$ \\
\hline Lysine acetylsalicylate & 900 mg orally & A \\
\hline Naproxen & $500-1,000$ mg orally & A \\
\hline Diclofenac & 50-100 mg orally & A \\
\hline Ibuprofen & $200-800 \mathrm{mg}$ orally & A \\
\hline Metamizole sodium & $1,000 \mathrm{mg}$ orally & B \\
\hline Tolfenamic acid & $200-400$ mg orally & B \\
\hline $\begin{array}{l}\text { ASA + acetaminophen } \\
\text { + caffeine }\end{array}$ & $\begin{array}{l}250 \mathrm{mg}+200 \mathrm{mg} \\
+50 \mathrm{mg} \text { orally }\end{array}$ & A \\
\hline Metoclopramide & $10-20$ mg orally & B \\
\hline Ergotamine & $1-2$ mg orally & B \\
\hline Dihydroergotamine & $1-2$ mg orally & B \\
\hline Sumatriptan & $\begin{array}{l}25-50-100 \text { mg orally, } \\
25 \text { mg rectally, } \\
10-20 \text { mg nasal spray, } \\
6 \text { mg subcutaneously }\end{array}$ & A \\
\hline Zolmitriptan & $\begin{array}{c}2.5-5.0 \text { mg orally/ } \\
\text { nasal spray }\end{array}$ & A \\
\hline Rizatriptan & 10 mg orally & $A$ \\
\hline Eletriptan & $40-80 \mathrm{mg}$ orally & $A$ \\
\hline Naratriptan & $2.5-5.0 \mathrm{mg}$ orally & $A$ \\
\hline
\end{tabular}

Table 11. Guidelines for treatment of migraine attack based on evidence-based medicine criteria. Class A recommendation: results based on controlled, multi-centre, randomised, double-blind studies. Class B recommendation: results based on randomised studies and recommendations of scientific societies. Class $C$ recommendation: recommendations based on those of the US Headache Consortium with no randomised and controlled trials [63]

\begin{tabular}{lcc}
$\begin{array}{l}\text { Class A recom- } \\
\text { mendation }\end{array}$ & $\begin{array}{c}\text { Class B recom- } \\
\text { mendation }\end{array}$ & $\begin{array}{r}\text { Class C recom- } \\
\text { mendation }\end{array}$ \\
\hline $\begin{array}{l}\text { ASA } \\
\text { ASA + acetaminophen + } \\
\text { caffeine }\end{array}$ & $\begin{array}{r}\text { ASA + barbiturates } \\
\text { + caffeine }\end{array}$ \\
ASA + metoclopraminophen & $\begin{array}{c}\text { Corticosteroids } \\
\text { Naproxen }\end{array}$ \\
Ibuprofen & Parenteral opioids \\
Tolfenamic acid & Flurbiprofen & \\
DHE nasal spray & \\
Triptans & \\
Butorphanol nasal spray & \\
ASA - acetylsalicylic acid;DHE - dihydroergotamine
\end{tabular}

\section{Treatment of migraine with prolonged aura}

Definition: Focal neurological symptoms preceding the headache with autonomic symptoms that fulfill the criteria for a migraine attack without aura and which last longer than
Table 12. Drugs recommended for migraine aura lasting more than 30 minutes

\section{Treatment of prolonged aura}

Inhalation of mixture of $90 \%$ oxygen, $10 \%$ carbon dioxide

Nifedipine $10 \mathrm{mg}$, sublingually

Furosemide $20 \mathrm{mg}$, intravenously

Sodium valproate $500 \mathrm{mg}$, orally

Acetazolamide $250 \mathrm{mg}$, orally

Prochlorperazine $5 \mathrm{mg}$, orally

Magnesium sulfate $200 \mathrm{mg}$, intravenously or $600 \mathrm{mg}$ as continuous infusion

60 minutes. Drugs recommended for migraine aura lasting more than 30 minutes are set out in Table 12.

\section{Other drugs that may be useful for the treatment of migraine attacks}

Clinical studies have demonstrated that valproic acid is effective for the treatment of severe migraine attacks $[64,65]$. In an open-label study, headache relief within 30 minutes after infusion with $300 \mathrm{mg}$ of valproic acid was reported in $56 \%$ of patients [66]. Similar efficacy was reported after administration of a $500 \mathrm{mg}$ dose [67]. A $1 \mathrm{~g}$ dose of intravenous valproic acid given over one hour, followed by the administration of 500-1,000 mg per day for the following days also exerted beneficial effects [68]. Intravenous magnesium sulfate at a dose of 300-1,000 mg was found to be effective for the acute treatment of migraine [69]. This could be an alternative for patients with a migraine attack who cannot take ergotamine or triptans due to coexisting vascular disease, as well as for patients whose major problem is aura, especially prolonged aura.

Ditans and new-generation gepants are a new option for the acute treatment ofmoderate-to- severe migraine. Lasmidi$\tan$ is the first drug in the ditans class to have been approved by the FDA (in 2019) for acute migraine treatment [70]. It binds to the 5-HT1F receptor subtype, so it does not constrict blood vessels $[71,72]$. This makes it safer than triptans for people with contraindication for triptans [73-75].

Recently, the FDA has also approved ubrogepant and rimegepant for the acute treatment of migraine with or without aura in adults. They are the first oral CGRP receptor antagonists approved by the FDA. Ubrogepant and rimegepant, similarly to monoclonal antibodies (nAbs) against 'CGRP-pathways', are supposed to prevent the dilation of intracranial vessels instead of constricting them, so, if used abortively, they are also an alternative to triptans [76].

As of December 2020, neither ditans nor gepants have been approved by the EMA for the acute treatment of migraine, and are not yet available in Poland. 


\section{Preventive treatment of migraine (episodic and chronic forms)}

Preventive treatment is recommended for patients with frequent episodic migraine (especially for patients who experience attacks that last longer than 24 hours and/or that do not resolve after acute treatment), and for those with chronic migraine.

In these patients, pharmacotherapy and psychotherapy should be used simultaneously. Acute treatment for chronic migraine does not generally differ from the recommended treatment of episodic migraine. Before initiating pharmacotherapy, therapy goals and the possibilities of reducing the incidence of attacks, the expected duration of treatment and side effects should be explained to the patient, who should approve the procedures. In those whose treatment does not result in sufficient improvement, adding a second drug from another group is recommended. The efficacy of preventive treatment is limited, and a reduction in the frequency of attacks is achieved in some patients only. The new generation of drugs [monoclonal antibodies against Calcitonin-Gene Related Peptide (CGRP) or against the CGRP receptor] show high efficacy along with a very good safety profile. None of the older-

generation drugs have a therapeutic gain of more than $50 \%$; such a gain is defined as the difference between the proportion of patients responding to the active drug minus the proportion of patients responding to a placebo. Preventive treatment failures of any therapy can be associated with too short treatment time, inadequate dosing, simultaneous overuse of analgesics, the occurrence of side effects, or an incorrect drug selection for a patient. The new generation of drugs, due to their good tolerability, can be used for many months. It is recommended that treatment with first-line drugs should last for at least three months, but the average duration is six months - only the use of flunarizine is limited to a maximum of three months, after which there has to be a complete break of more than three months. Some patients require even longer pharmacotherapy.

\section{Chronic migraine}

Patients who experience headaches on 15 or more days per month for more than three months, with the features of migraine headache on at least eight of those days, should be diagnosed with chronic migraine. Chronic migraine was previously known as 'transformed migraine', a term which dates back to 1990 and referred to the phenomenon of the transformation of infrequent episodic migraine to frequent episodic migraine and finally to headaches occurring every, or almost every, day.

Chronic migraine is defined as a headache occurring on 15 or more days per month that fulfills the diagnostic criteria for migraine or is relieved by triptans or ergotamine on at least eight days per month, and that derives from a type of headache
Table 13. Diagnostic criteria for chronic migraine

A. Headache (resembling tension-type and/or migraine-like headache) occurring at least 15 days per month for more than three months, and fulfilling criteria $B$ and $C$

B. Occurs in a patient who has had at least five attacks fulfilling criteria B-D for migraine without aura and/or criteria B and C for migraine with aura

C. On at least eight days per month for more than three months, fulfills any of the following characteristics:

1. Fulfills criteria $C$ and $D$ for migraine without aura

2. Fulfills criteria $B$ and $C$ for migraine with aura

3. According to the patient, it is migraine at onset and is relieved after taking triptan or ergot alkaloid

D. Disorders are not better accounted for by another ICHD-3 diagnosis

that previously fulfilled the criteria for episodic migraine with or without aura. The diagnostic criteria for chronic migraine are set out in Table 13.

The prevalence of chronic migraine in the European and North American populations is estimated to be $1.5-2 \%$. Epidemiological studies on migraine have demonstrated that the transformation of episodic to chronic migraine leads to a considerable increase in patient disability and a decrease in quality of life. This is associated with a significant increase of absenteeism and lost productivity, which entails significant economic and social costs. Patients with chronic migraine seek medical care and consult specialists more often than patients with episodic migraine, which increases the financial burden of healthcare [77-79]. Keeping a headache diary to note the days with headaches, the severity of headaches, the occurrence of other symptoms, and the number and doses of medications used, is highly recommended. Recognised factors that contribute to the transformation of episodic to chronic migraine are divided into three groups and set out in Table 14 [80].

As chronic migraine persists, its clinical features start to resemble those of tension-type headache: the intensity of pain decreases, aura and vegetative symptoms resolve, and pain is more likely to occur but is less intense during the attack. Over time, headaches occur daily or almost daily. During this period, there are at least eight days of migraine monthly. The goals of preventive therapy are set out in Table 15 , and the indications for the preventive treatment of migraine in Table 16.

Among first-line drugs, the most commonly used are antiepileptics and antidepressants, whereas in the treatment of frequent episodic migraine, beta-blockers and calcium channel blockers are most commonly used (Table 17) [81-85].

Propranolol (40-240 mg per day, usually $120-160 \mathrm{mg}$ per day) has long been used in the treatment of frequent episodic migraine. Its use is supported by level A evidence and it is recommended as a first-line medication [86]. Meta-analyses evaluating the efficacy of propranolol show that it reduces the incidence of migraine attacks compared to a placebo (44\% vs $14 \%$ ) [87]. Although the benefit-risk ratio of propranolol is 
Table 14. Factors contributing to the development of chronic migraine

Non-modifiable factors (or low modifiability)
- Age
- Female gender
- White race (Caucasian)
- Low education and socioeconomic status
- History of head injuries
Modifiable factors
- High frequency of migraine attacks
- Obesity
- Medication overuse, including caffeine as a stimulant and as a com-
ponent of medicines
- Snoring
- Coexistence of migraine and other pain syndromes
- Stress
Factors likely to influence migraine chronicity
- Genetic factors
- Occurrence of allodynia during an attack
- Concurrent inflammation
- Pro-thrombotic states

\section{Table 15. Goals of preventive therapy}

To reduce the frequency, severity, and duration, of migraine attacks, as well as the degree of disability during the attack

To increase the responsiveness to acute treatment and to reduce the use of abortive medications

To improve functional status during the attack and the patient's quality of life

To reduce treatment costs

\section{Table 16. Indications for preventive treatment of migraine}

Headache on $4+$ days per month, or four days with headache that
produce severe disability, or three days with severe headache that
requires staying in bed
Migraine attacks that do not respond to acute treatment
Contraindications to acute treatment
Acute treatment not tolerated
Use of 10+ pain relief tablets per month because of migraine attacks
Frequent migraine attacks (four or more days with migraine headache
per month) responding to acute treatment in patients who are at risk
of developing medication overuse headache
Uncommon migraine attacks (hemiplegic migraine, basilar migraine,
prolonged migraine aura)
Migraine attacks after migrainous infarction

favourable, one in six patients discontinues treatment due to side effects [88]. The most common side effects are

hypotonia, bradycardia, impaired glucose tolerance, dizziness, blurred vision, gastrointestinal disorders, potency disorders, and weight gain (weight gain of over $6 \mathrm{~kg}$ in $8 \%$ of
Table 17. First-line oral drugs used to treat episodic migraine, doses, and class of recommendation

\begin{tabular}{|c|c|c|}
\hline Drug & Daily dose & $\begin{array}{l}\text { Class of recom- } \\
\text { mendation }\end{array}$ \\
\hline \multicolumn{3}{|l|}{ Beta-blockers } \\
\hline Propranolol & $40-240 \mathrm{mg}$ & A \\
\hline Metoprolol & $50-200 \mathrm{mg}$ & $A$ \\
\hline \multicolumn{3}{|c|}{ Calcium channel blockers } \\
\hline Flunarizine & $5-10 \mathrm{mg}$ & B \\
\hline \multicolumn{3}{|c|}{ Antiepileptic drugs } \\
\hline Valproic acid* & $500-1,500 \mathrm{mg}$ & $A$ \\
\hline Topiramate & $25-200 \mathrm{mg}$ & $A$ \\
\hline \multicolumn{3}{|c|}{ Antidepressants } \\
\hline Amitriptyline & $50-150 \mathrm{mg}$ & B \\
\hline
\end{tabular}

patients) [89]. Propranolol is classified in pregnancy category C [90]. Rapid withdrawal may result in a sharp increase in blood pressure. An alternative to propranolol is metoprolol at a dose of 50-200 mg per day.

Another drug used to treat migraine with frequent attacks is flunarizine [91]. It is administered at a dose of 5-10 mg per day, often in combination with other drugs recommended in the treatment of chronic migraine. Long-term use (more than three months) of this medicine can cause extrapyramidal symptoms and depression in elderly patients.

Of the two antiepileptic drugs recommended for the prevention of migraine, topiramate is preferred over valproic acid. Its efficacy has been confirmed in large, multicentre, placebo- controlled trials $[92,93]$. Topiramate has been shown to inhibit cortical depolarisation (a key component of migraine pathogenesis) by suppressing trigeminal nociceptive neuronal activity [94, 95].

Topiramate is effective for the treatment of migraine (both frequent episodic and chronic) at doses of 100-200 $\mathrm{mg}$ per day and is well tolerated within this therapeutic range. These doses have not been exceeded in most studies. Opinions can be found in the literature stating that lower doses of up to $100 \mathrm{mg}$ per day are sufficient, while higher doses are associated with more side effects. Common side effects of topiramate are paresthesias, fatigue, attention deficit disorders, emotional lability, depression, weight loss (in about two thirds of patients), diarrhoea, and sleepiness [96]. There have been reports that topiramate impairs cognitive function and memory and worsens depression, which imposes major limitations on the use of this medicine. If monotherapy does not yield the expected effects, combining topiramate with beta-blockers is beneficial [97]. The number of patients benefitting from

treatment with topiramate decreases gradually over time: after a 9-month period the drug maintains remission in $40 \%$ 
of patients, whereas after 12 months remission is maintained in only a third of patients [98]. Slightly less than $30 \%$ of patients discontinue treatment due to side effects [99]. Topiramate should not be taken by women who are pregnant because of potential teratogenic effects (pregnancy category D) [100].

In a large placebo-controlled trial, Klapper confirmed the efficacy of valproic acid at a dose of $500-1,000 \mathrm{mg}$ per day [101]. Treatment with this drug is associated with a risk of side effects including hepatotoxicity, hair loss, and significant weight gain (the latter two are frequently observed). Additionally, this drug exerts teratogenic effects, and therefore cannot be used by pregnant women or those planning to become pregnant. According to the European Medicines Agency (EMA) recommendations, valproic acid should not be used in young women with childbearing potential (US Food and Drug Administration (FDA) Category X) [102, 103].

The European Neurological Society and the American Academy of Neurology recommend that amitriptyline should be considered a second-choice drug (category B evidence). The drug is widely used in patients with coexisting tension-type headache, depression, or emotional lability. Like antiepileptic drugs, amitriptyline causes side effects that discourage patients from long-term therapy. The most common side effects are weight gain (64.5\%), dry mouth and dry eye syndrome (35.5\%), sleepiness (11.9\%), and a feeling of constant tiredness or exhaustion (16.9\%) [104, 105]. The drug is contraindicated in patients with glaucoma, asthma, arrhythmia, hypertension, prostate hyperplasia, and urinary retention. Cardiovascular side effects include atrioventricular block, hypotonia, and tachycardia [106]. Therefore, it is recommended that electrocardiography (ECG) be performed before initiating therapy, again two weeks after initiating therapy, and again when increasing the dose by $50 \%$ from the initial dose. In most patients, doses of 50-100 mg have been found to be sufficient [107]. Higher doses are rarely used. The concentration

of drug in the blood does not correlate with its analgesic effect [108]. The first beneficial effect of amitriptyline is quickly noticeable, even after one week of treatment [109].

Botulinum toxin A (BoNT-A, BOTOX product) has been shown to be effective as a preventive treatment for chronic migraine (Table 18) [110]. BoNT-A has comparable efficacy to topiramate, but is better tolerated. BoNT-A is a neurotoxin that acts locally and inhibits the release of acetylcholine (and probably other neurotransmitters more involved in migraine pathophysiology) from presynaptic parasympathetic terminals and sympathetic cholinergic postganglionic fibres (and probably in the trigeminal system), causing local chemical denervation. Therapy with BoNT-A injections (155-195 U to 31-39 sites according to the PREEMPT paradigm) should be repeated every 12 weeks (not more frequently) several times, even if neither the first nor the second administration produces the expected therapeutic effect. Doses and injection sites for BoNT-A are set out in Table 19. In some patients, improvement is achieved only after the second or even the third
Table 18. Drugs (including BoNT-A) used to treat chronic migraine, doses, and class of recommendation

\begin{tabular}{lcc|}
\hline Drug & Daily dose & $\begin{array}{c}\text { Class of recom- } \\
\text { mendation }\end{array}$ \\
\hline $\begin{array}{l}\text { Antiepileptic drugs } \\
\text { Valproic acid }\end{array}$ & $500-1,500 \mathrm{mg}$ & $\mathrm{A}$ \\
$\begin{array}{l}\text { Topiramate } \\
\text { Antidepressants }\end{array}$ & $25-200 \mathrm{mg}$ & $\mathrm{A}$ \\
Amitriptyline & $50-150 \mathrm{mg}$ & $\mathrm{B}$ \\
Others & $150-195 \mathrm{I.U}$. & \\
BoNT-A & A/B \\
BoNT-A - botulinum toxin A & every 12 weeks & \\
\hline
\end{tabular}

Table 19. Doses of BoNT-A and injection sites

\begin{tabular}{lcc|}
\hline Muscle & $\begin{array}{c}\text { Recommended } \\
\text { dose }\end{array}$ & $\begin{array}{c}\text { Number of injection } \\
\text { sites }\end{array}$ \\
\hline Frontalis & $20 \mathrm{U}$ & 4 \\
Procerus & $5 \mathrm{U}$ & 1 \\
Occipitalis & $30-40 \mathrm{U}$ & $6-8$ \\
Temporalis & $40-50 \mathrm{U}$ & $8-10$ \\
Trapezius & $30-50 \mathrm{U}$ & $6-10$ \\
Cervical paraspinal & $20 \mathrm{U}$ & 4 \\
Total & $155-195 \mathrm{U}$ & $31-39$
\end{tabular}

BoNT-A - botulinum toxin A

administration of BoNT-A. Side effects occur rarely (in only approximately $5 \%$ of patients) and are mild and transient. The most commonly observed side effects are brow ptosis, eyelid ptosis, neck muscle weakness, and (less frequently) a flu-like syndrome. Patients receiving higher doses can experience temporary double vision. This can be avoided by injecting more upper parts of forehead muscles, because its local effect is limited to an area of about 3-4 cm around the site of administration. It is recommended that treatment with botulinum toxin during a period of sustained clinical improvement should be continued over an extended time to prevent the recurrence of chronic migraine [111]. Extending the interval between injections to more than three months is associated with reduced treatment efficacy; the administration of the drug once every four months has been shown to be effective at not increasing the frequency of headaches in only one-third of patients [112].

Discontinuing treatment with BoNT-A can lead to an increase in the number of days with headaches, which is the reason for resuming therapy. The optimal timing of preventive treatment with BoNT-A has not been established [113]. Risk factors for early recurrence of chronic migraine in patients who achieved a reduction in the number of days with headache include a large number of such days before the treatment, the overuse of analgesics, and prior preventive treatment failure [114]. In 2016, the American Academy of Neurology 
recommended BoNT-A in the treatment of chronic migraine to improve quality of life (level B) and to increase the number of headache-free days (level A) [115].

New-generation drugs for migraine prophylaxis - monoclonal antibodies against CGRP and the CGRP receptor

Monoclonal antibodies ( $\mathrm{mAbs}$ ) are directed against CGRP receptor (erenumab) or CGRP itself (fremanezumab, galcanezumab, and eptinezumab). All registration studies have shown that these drugs are safe and highly effective at reducing the number of days with headache and migraine attacks. Moreover, patients took fewer acute headache medicines per month than patients receiving a placebo.

The key advantages of $\mathrm{mAbs}$ are the high efficacy and dosage regimen (every four or 12 weeks depending on medication and dose), the absence of serious side effects, and that there is no need to increase the dose gradually $[116,117]$. The fast onset of action (in the first week following administration), high efficacy, and good tolerability make this class of drugs superior to the oral therapies that have been used so far [118]. mAbs are the first specific compounds affecting the most probable mechanism of migraine attacks. The administration of mAbs can result in the production of neutralising antibodies. However, studies and observations have hitherto shown that following administration of mAbs directed against CGRP or its receptor, neutralising antibodies are produced rarely and in small amounts, and do not impede a favourable clinical response. The efficacy of these drugs for the treatment of migraine in patients with CADASIL (cerebral autosomal dominant arteriopathy with subcortical infarcts and leukoencephalopathy) has also been reported [119].

The American Academy of Neurology and the European Neurological Federation approve the use of $\mathrm{mAbs}$ for the prevention of migraine in patients aged 18 years or older who are diagnosed with chronic migraine according to the ICHD-3 criteria or who have episodic migraine with at least four headache days per month, and in those who did not tolerate, or had no response to, at least a 6-week treatment trial with at least two of the following drugs: topiramate, valproic acid, beta-blockers (metoprolol, propranolol, timolol, atenolol, nadolol), tricyclic antidepressants (amitriptyline, nortriptyline), serotonin reuptake inhibitors (venlafaxine, duloxetine) or other level A or B treatments, and, in the case of chronic migraine, also BoNT-A (Table 20) [120]. Monoclonal antibodies directed against CGRP used to treat migraine are set out in Table 21.

Evaluation of the efficacy of mAbs in clinical trials included individuals aged $18-65$ years. There is no data available to indicate whether these drugs are equally effective and safe in those aged under 18 or over 65 . Long-term studies did not show any side effects of treatment other than those reported in the registration studies. Current European treatment guidelines for chronic migraine do not recommend the use of $\mathrm{mAbs}$ in pregnant or breastfeeding women, or in people with cardiovascular diseases, alcohol and drug use disorders, or mental disorders [121]. Treatment efficacy should be assessed
Table 20. Indications for treatment with monoclonal antibodies developed by the American Academy of Neurology

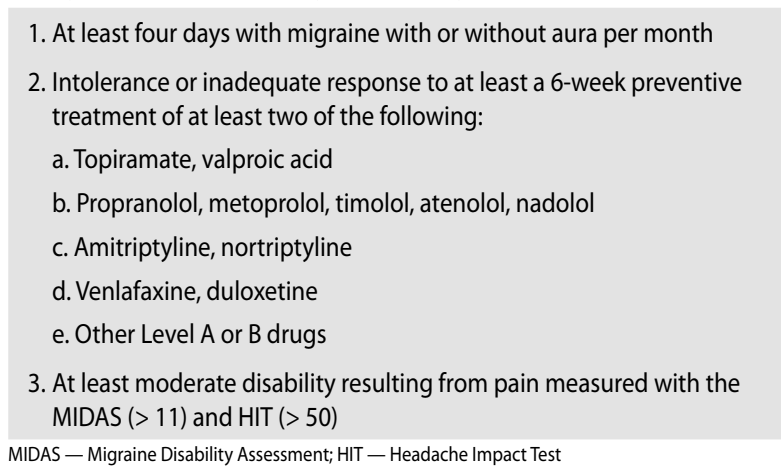

Table 21. Monoclonal antibodies directed against CGRP used to treat migraine

\begin{tabular}{|c|c|c|}
\hline Antibody & Indication & $\begin{array}{l}\text { Dosage and route } \\
\text { of administration }\end{array}$ \\
\hline \multirow[t]{2}{*}{ Erenumab } & \multirow[t]{2}{*}{$\begin{array}{l}\text { Episodic migraine, } \\
\text { Chronic migraine }\end{array}$} & $\begin{array}{l}140 \text { mg or } 70 \text { mg per month } \\
\text { subcutaneously once per } \\
\text { month; binds to CGRP receptor }\end{array}$ \\
\hline & & $\begin{array}{l}\text { A fully human monoclonal } \\
\text { antibody }\end{array}$ \\
\hline \multirow[t]{2}{*}{ Eptinezumab } & \multirow[t]{2}{*}{ Chronic migraine } & $\begin{array}{l}300 \mathrm{mg} \text { or } 100 \mathrm{mg} \text { per } \\
\text { month intravenously once } \\
\text { per month; binds to CGRP }\end{array}$ \\
\hline & & $\begin{array}{l}\text { Humanised antibody } \\
(90-95 \% \mathrm{H})\end{array}$ \\
\hline \multirow{3}{*}{$\begin{array}{l}\text { Fremane- } \\
\text { zumab }\end{array}$} & \multirow{3}{*}{$\begin{array}{l}\text { Episodic migraine, } \\
\text { Chronic migraine }\end{array}$} & 225 mg subcutaneously \\
\hline & & $\begin{array}{l}\text { once per month, or } 6 / 5 \mathrm{mg} \\
\text { once every three months } \\
\text { subcutaneously; binds } \\
\text { to CGRP }\end{array}$ \\
\hline & & $\begin{array}{l}\text { Humanised antibody } \\
(90-95 \% \mathrm{H})\end{array}$ \\
\hline \multirow[t]{3}{*}{ Galcanezumab } & \multirow{3}{*}{$\begin{array}{l}\text { Episodic migraine, } \\
\text { Chronic migraine }\end{array}$} & $120 \mathrm{mg}$ or $240 \mathrm{mg}$ per \\
\hline & & $\begin{array}{l}\text { month subcutaneously once } \\
\text { per month; binds to CGRP }\end{array}$ \\
\hline & & $\begin{array}{l}\text { Humanized antibody } \\
(90-95 \% \mathrm{H})\end{array}$ \\
\hline
\end{tabular}

and the decision about the continuation of treatment made 3-6 months after the first administration of mAbs. Treatment is considered to be effective if at least one of the following is achieved:

1. A reduction in monthly headache days of $50 \%$ relative to the pretreatment month (analysis based on the patient's diary is recommended but not required)

2. Functional improvement of the patient assessed as a Migraine Disability Assessment (MIDAS) score of at least 5 points, with a baseline score ranging from 11 to 20

3. A reduction in MIDAS score of $30 \%$ for patients achieving values close to 20 at baseline or a functional improvement assessed using other scores (e.g. Migraine Physical Function 
Table 22. Drugs with a probably beneficial effect on chronic migraine

\begin{tabular}{lll|} 
Drug & \multicolumn{1}{c}{ Daily dose } & $\begin{array}{c}\text { Class of recommen- } \\
\text { dation }\end{array}$ \\
\hline Acetylsalicylic acid & $300 \mathrm{mg}$ & $\mathrm{C}$ \\
Gabapentin & $1,200-1,600 \mathrm{mg}$ & $\mathrm{C}$ \\
Magnesium & $24 \mathrm{mmol}$ & $\mathrm{C}$ \\
Riboflavin & $400 \mathrm{mg}$ & $\mathrm{C}$ \\
Coenzyme Q10 & $300 \mathrm{mg}$ & $\mathrm{C}$
\end{tabular}

Table 23. Diagnostic criteria for medication-overuse headache

A. Headache occurring on at least 15 days per month in a patient
with a pre-existing headache syndrome
B. Regular overuse for more than three months of one or more
drugs used for acute and/or symptomatic treatment of heada-
che (on the abovementioned number of days)
C. Disorders are not better accounted for by another ICHD-3
diagnosis

Impact Diary (MPFID), 6-item Headache Impact Test (HIT-6), or improvement documented in the patient's diary.

Many experts, including national experts, state that its very good safety profile and high clinical efficacy make mAbs the first-line treatment for chronic migraine and even for frequent episodic migraine.

Currently, there is no data indicating the impact of treatment with mAbs on the course of SARS-CoV-2 infection.

Other drugs for preventive treatment of frequent episodic migraine and chronic migraine are rarely used because the clinical efficacy of most drugs has not been proven. Preventive treatment is discontinued if the frequency of migraine attacks remains relatively stable, which can be observed after approximately six months, and results in gradual dose reduction. If gradual dose reduction leads to the exacerbation and recurrence of frequent migraine attacks, dose escalation and the continuation of therapy for the next 6-9 months are recommended. Drugs with a probably beneficial effect on chronic migraine are set out in Table 22.

\section{Medication-overuse headache ( $\mathrm{MOH})$ - a symptomatic headache (according to ICHD-3) being a common complication of migraine}

Patients with migraine commonly overuse medications, especially analgesics. Migraine chronification can be both the effect of, and the reason for, overusing medications, which leads to $\mathrm{MOH}$ (Table 23). The medicines that are most likely to increase the frequency of migraine attacks or to generate
$\mathrm{MOH}$ are triptans, ergotamine, opioids, simple and combination analgesics, and NSAIDs. The risk of developing $\mathrm{MOH}$ increases significantly when taking acute medications in higher doses than the following:

- Triptans (intake on at least 10 days per month for at least three months)

- Ergotamine (intake on at least 10 days per month for at least three months)

- Opioids (intake on at least 10 days per month for at least three months)

- Combination analgesics (intake on at least 10 days per month for at least three months)

- Simple analgesics (intake on at least 15 days per month for at least three months)

- NSAIDs (intake on at least 15 days per month for at least three months).

It is recommended that the initiation of preventive treatment should be considered in every patient with migraine taking more than two doses of acute medications per week [122].

In the case of $\mathrm{MOH}$, complete withdrawal of the analgesics that cause this type of headache, and possibly the initiation of preventive treatment with drugs that are also used to treat chronic migraine (topiramate, BoNT-A) are recommended. During the first days after the abrupt withdrawal of the medication(s) that were overused, worsening of headaches (i.e. increased frequency and intensity) can occur. In such patients, $60 \mathrm{mg} /$ day of prednisone (or prednisolone) or up to $50 \mathrm{mg} /$ day of amitriptyline can be used.

\section{Treatment of menstrual migraine}

About $7.5-21 \%$ of women with migraine have most attacks during menstruation (from two days before the onset of menstruation to three days after it ends) $[123,124]$.

Headache affects $48-90 \%$ of women with premenstrual syndrome [125]. Perimenstrual headaches are thought to be caused by hormonal changes that occur in women during that time. Migraine attacks coexist with mood disorders, depression, emotional lability, and somatic symptoms, such as menstrual cramps, feeling of breast heaviness, and swelling of the hands and feet. Migraine attacks occur most commonly five days before the expected onset of menstruation and vanish up to four days after menstruation ends. Menstrual migraine is usually without aura. Attacks that occur during menstruation are characterised by higher pain intensity, frequent recurrence, and poor response to applied treatment [126-128]. The administration of oestrogens during the perimenstrual period can reduce frequency of attacks in $72 \%$ of patients who have migraine with aura, and in $43 \%$ of patients who have migraine without aura [129]. The diagnostic criteria for pure menstrual migraine are set out in Table 24 and the diagnostic criteria for menstrually-related migraine in Table 25.

Naproxen sodium (550 mg twice daily) has proven effective in treating menstrual migraine (Table 26). This treatment reduces migraine pain before and during menstruation [130]. 
Table 24. Diagnostic criteria for pure menstrual migraine

A. Migraine attacks in menstruating women, fulfilling the criteria for migraine without aura (or migraine with aura) as above, and criterion B

B. Attack occurs two days before the expected onset of menstruation and lasts for three days in at least two of three menstrual cycles, and on no other days of the cycle

\section{Table 25. Diagnostic criteria for menstrually-related migraine}

A. Migraine attacks in menstruating women, fulfilling the
criteria for migraine without aura (or migraine with aura) as
above, and criterion B
Attack occurs two days before the expected onset of
menstruation and lasts for three days in at least two of three
menstrual cycles, and also occurs on other days of the cycle

Table 26. Treatment of menstrual migraine

\begin{tabular}{|c|}
\hline NSAIDs: \\
\hline Naproxen $500-750$ mg per 24 hours \\
\hline Diclofenac $50-150$ mg per 24 hours \\
\hline Metamizole $500-1,500 \mathrm{mg}$ per 24 hours \\
\hline Triptans \\
\hline Sumatriptan $50-100 \mathrm{mg}$ per 24 hours \\
\hline Zolmitriptan 5-10 mg per 24 hours \\
\hline Rizatriptan 10 mg per 24 hours \\
\hline Eletriptan $40-80 \mathrm{mg}$ per 24 hours \\
\hline Frovatriptan $2.5-5.0 \mathrm{mg}$ per 24 hours \\
\hline Naratriptan $2.5-5.0 \mathrm{mg}$ per 24 hours \\
\hline Other drugs \\
\hline Ergotamine $0.5-1.0 \mathrm{mg}$ per 24 hours \\
\hline Oestradiol $100 \mathrm{mg}$ patches, from $48 \mathrm{~h}$ before menstruation for six days \\
\hline Danazol 200-400 mg per 24 hours \\
\hline Bromocriptine $7.5 \mathrm{mg}$ per 24 hours \\
\hline Tamoxifen $10-20$ mg per 24 hours \\
\hline Magnesium supplements $360 \mathrm{mg}$ per 24 hours \\
\hline
\end{tabular}

Use of triptans with a long serum half-life is also recommended, such as $2.5 \mathrm{mg}$ of frovatriptan twice daily for five days, including two days before the onset of menstruation, and naratriptan twice daily for five days $(2 \times 2.5 \mathrm{mg})$, starting two days before the expected onset of menstruation [131, 132]. Another method of treating menstrual migraine is based on hormone replacement therapy with oestrogen. This therapy is less effective than beta-blockers or other first- and second-line drugs. The administration of percutaneous oestradiol at $<$ $100 \mu \mathrm{g}$ for six days during the perimenstrual period is recommended [133].

\section{Treatment of migraine during pregnancy and breastfeeding}

No reliable data from clinical trials on the safety of migraine treatment during pregnancy and breastfeeding have been obtained so far. Nevertheless, the use of paracetamol is recommended as the drug of first choice for aborting migraine attacks. After the first trimester, NSAIDs may be used if clinically indicated. Ergotamine and ergot derivatives are contraindicated. Triptans can be used in special circumstances, but are not recommended because their safety has not been confirmed. Data from a registry of women who were taking sumatriptan showed that the risk of birth defects in the first trimester was $1.2 \%$, with the percentage of defects recorded in the general population being 3-5\% [134]. It is thought that treatment with triptans is not contraindicated in breastfeeding women because only $10 \%$ of the dose is excreted into the milk.

Only magnesium sulfate and metoprolol (level B recommendation) are recommended for the preventive treatment of migraine during pregnancy [135]. However, supraorbital and supratrochlear nerve stimulation (e.g. CEFALY ${ }^{\circ}$ device) seems to be the safest option of treatment.

\section{Treatment of status migrainosus}

Definition: a severe migraine attack lasting for more than 72 hours is termed status migrainosus (Table 27). A patient usually remains in bed, and, due to acute nausea or vomiting, is unable to take food, which leads to dehydration and general deterioration. The patient is more sensitive to light and sound, isolates, and avoids migraine triggers such as lights, sounds, and smells. Inpatient treatment is recommended, especially for people who are exhausted due to long-lasting severe pain accompanied by vomiting, nausea, and dehydration, as well as for people who overuse medications.

Firstly, fluid and electrolyte imbalances should be corrected. People who overuse analgesics, ergotamine, or triptans should stop their medication. Drugs recommended for the treatment of status migrainosus are set out in Table 28.

Currently, a combination of NSAIDs, triptans, and antiemetics or, in certain cases, a combination of triptan with a small dose of steroid (e.g. dexamethasone $4 \mathrm{mg}$ ) are considered most effective for aborting a severe migraine attack.

Table 27. Diagnostic criteria for status migrainosus

1. Migraine attack fulfilling the criteria for migraine without aura except the criterion for its duration

2. Headache fulfilling the following conditions:

a. Unremitting headache that lasts for more than 72 hours

b. High pain intensity

3. Headache not attributed to another disorder 
Table 28. Treatment of status migrainosus

\begin{tabular}{lc} 
Drug name & Daily dose \\
\hline $\begin{array}{l}\text { Sumatriptan (subcutaneous, nasal spray, or } \\
\text { per rectum) }\end{array}$ & $6-50 \mathrm{mg}$ \\
Dexamethasone (intravenous) & $16 \mathrm{mg}$ \\
Hydrocortisone (intravenous) & $100-500 \mathrm{mg}$ \\
Methylprednisolone (intravenous) & $100-500 \mathrm{mg}$ \\
Prochlorperazine (intravenous) & $5-10 \mathrm{mg}$ \\
Chlorpromazine (intravenous) & $12.5-50.0 \mathrm{mg}$ \\
Dihydroergotamine (intravenous) & $0.5-1.0 \mathrm{mg}$ \\
Ergotamine (subcutaneous) & $0.25 \mathrm{mg}$ \\
Valproic acid (intravenous) & $1,000-2,000 \mathrm{mg}$ \\
Droperidol (intravenous, intramuscular) & $2.2-8.5 \mathrm{mg}$ \\
Metoclopramide (intravenous) & $10 \mathrm{mg}$ \\
Diazepam (intramuscular) & $5-10 \mathrm{mg}$ \\
Magnesium sulfate (intravenous) & $300-1,000 \mathrm{mg}$
\end{tabular}

Antipsychotics, especially phenothiazine derivatives (e.g. chlorpromazine $25 \mathrm{mg}$ and prochlorperazine $10 \mathrm{mg}$ ), are effective for the treatment of status migrainosus. Moreover, the use of droperidol 2.75-8.25 mg and haloperidol 5-8 mg administered intravenously or preferably intramuscularly, is recommended [136]. Numerous studies evaluating the efficacy of this class of drugs for the treatment of migraine attacks have shown that headache relief was achieved in $60-75 \%$ of patients [137]. Prochlorperazine was found to be effective and safe for the treatment of severe migraine attacks including in children [138]. These drugs are dopamine agonists and relieve the headache and symptoms associated with migraine, such as nausea, vomiting, and photophobia. Indications for their use include migraine attacks nonresponsive to other drugs or severe migraine attacks if ergotamine, triptans, or steroids are contraindicated. ECG (due to risk of QT prolongation) and measurement of serum calcium and potassium levels are recommended before intravenous administration of antipsychotics.

These drugs, when taken at recommended doses, are safe and cause relatively few side effects, of which the most common are psychomotor slowing, sleepiness, hypotension, tachycardia, dyskinesia, and akathisia. Benzodiazepines (e.g. diazepam 5-10 mg) can also be useful in treating status migrainosus [139]. Intravenous administration of $20 \mathrm{mg}$ of metoclopramide (four injections within two hours, up to a total dose of $80 \mathrm{mg}$ ) has been found to be effective. A double-blind, randomised trial demonstrated that this medication was as effective as $6 \mathrm{mg}$ of sumatriptan administered subcutaneously [140]. Within 24 hours after drug administration, relief of pain was observed in $40 \%$ of patients treated with metoclopramide and in $27 \%$ of patients treated with sumatriptan ( $\mathrm{p}$ $=0.23$ ); complete relief of pain was observed in $59 \%$ and $35 \%$ of patients, respectively.

\section{Non-pharmacological treatment of migraine}

Few randomised trials assessing the effect of non-pharmacological treatments for migraine have been carried out so far. Nevertheless, they are approved by many experts. Non- pharmacological therapies can be used independently, or in combination with pharmacotherapy, both during remission and during a period of frequent attacks. Use of relaxation training, cognitive behavioural therapies and electromyographic biofeedback is reasonable. It is vital to change lifestyle factors, especially sleeping patterns, food intake, and physical activity. Herbal medicine, largely ignored in recent years, and mineral (mainly magnesium) and vitamin (mainly pyridoxine and riboflavin) supplementation are also used [141]. To date, few randomised trials evaluating the efficacy of herbal medications for the prevention of migraine have been conducted. The efficacy of acupuncture and acupressure in the treatment of episodic and chronic migraine was comparable to that of a placebo. Neurostimulation techniques raise therapeutic possibilities, becoming an additional method of treatment for patients with migraine that is resistant to pharmacological therapy or for whom pharmacological therapy is contraindicated (e.g. during pregnancy).

Neurostimulation techniques used to treat migraine include a variety of methods such as peripheral nerve stimulation (or the peripherial nerve block [142, 143]) and transcranial magnetic stimulation. Peripheral nerve stimulation (occipital, supraorbital, and supratrochlear nerves) is a non-invasive, safe method for the treatment of primary headaches [144]. The CEFALY $^{\circledR}$ device is used for the treatment of most types of migraine, including preventive treatment of both episodic and chronic migraine. It emits micro-impulses that stimulate the supraorbital and supratrochlear nerves (branches of the trigeminal nerve), thus reducing the frequency of migraine attacks.

Other recommended (after achieving reliable results) treatments for episodic and chronic migraine include single-pulse transcranial magnetic stimulation, electrical stimulation of the trigeminal nerve, and non-invasive vagus nerve stimulation $[145,146]$.

The usefulness of physical exercise for the prevention of migraine has been underlined for many years, and the efficacy and usefulness of physical activity in the preventive treatment of migraine have been shown in a clinical trial [147].

Conflicts of interest: The authors have no conflict of interest to declare. The other Board Members of the Polish Headache Society were informed that the authors were writing these recommendations; they did not object, and declared no conflict.

\section{References}

1. Evers S, Afra J, Frese A, et al. European Federation of Neurological Societies. EFNS guideline on the drug treatment of migraine--revised report of an EFNS task force. Eur J Neurol. 2009; 16(9): 968-981, 
doi: 10.1111/j.1468-1331.2009.02748.x, indexed in Pubmed: 19708964.

2. Orr SL, Friedman BW, Christie S, et al. Management of adults with Acute Migraine in Emergency Department: The American Society Evidence Assessment of Parental Pharmacotherapies. Headache. 2016; 56: 911-940.

3. Domitrz I, Kozubski W. Rekomendacje diagnostyczno-terapeutyczne postępowania w migrenie. Pol. Przegląd Neurol. 2019; 15(supp.B): 1-20.

4. Stępień A. Rożniecki, Domitrz I. Leczenie pierwotnych bólów głowy. Ból. 2011; 12(4): 7-14.

5. Dodick DW Migraine Lancet. 2018; 391(10127): 1315-1330, doi: 10.1016/S0140-6736(18)30478-1.

6. Goadsby PJ, Holland PR. Migraine Therapy: Current Approaches and New Horizons. Neurotherapeutics. 2018; 15(2): 271-273, doi: 10.1007/s13311-018-0626-3, indexed in Pubmed: 29667112.

7. Worthington I, Pringsheim T, Gawel MJ, et al. Canadian Headache Society Acute Migraine Treatment Guideline Development Group. Canadian Headache Society Guideline: acute drug therapy for migraine headache. Can J Neurol Sci. 2013; 40(5 Suppl 3): S1-S80, indexed in Pubmed: 23968886.

8. Lipton RB, Bigal ME, Diamond M, et al. AMPP Advisory Group. Migraine prevalence, disease burden, and the need for preventive therapy. Neurology. 2007; 68(5): 343-349, doi: 10.1212/01. wnl.0000252808.97649.21, indexed in Pubmed: 17261680.

9. Społeczne znaczenie migreny z perspektywy zdrowia publicznego i systemu ochrony zdrowia. Nnational Institut of Public Health (pzh) Raport. : Warszawa.

10. Prencipe M, Gasini AR, Ferretti C. Prevalence of headache in an elderly population: attack frequency, disability, and use of medication. J Neurol Neurosurg Psychiatry. 2001; 70: 377-381.

11. Goldstein M, Chen TC. The Epidemiology of distabling headache. W: Critchley M, Advances in neurology. New York, Raven Press. 1982; 33: $377-390$.

12. Laurell $\mathrm{K}$, Artto V, Bendtsen L, et al. Premonitory symptoms in migraine: A cross-sectional study in 2714 persons. Cephalalgia. 2016; 36(10): 951-959, doi: 10.1177/0333102415620251, indexed in Pubmed: 26643378.

13. Denuelle M, Fabre N, Payoux P, et al. Hypothalamic activation in spontaneous migraine attacks. Headache. 2007; 47(10): 1418-1426, doi: 10.1111/j.1526-4610.2007.00776.x, indexed in Pubmed: 18052951.

14. May A, Bahra A, Büchel C, et al. Hypothalamic activation in cluster headache attacks. Lancet. 1998; 352(9124): 275-278, doi: 10.1016/ S0140-6736(98)02470-2, indexed in Pubmed: 9690407.

15. Kreczmański P, Wolak T, Lewandowska M, et al. Altered functional brain imaging in migraine patients: BOLD preliminary study in migraine with and without aura. Neurol Neurochir Pol. 2019; 53(4): 304-310, doi: 10.5603/PJNNS.a2019.0035, indexed in Pubmed: 31441496.

16. Chądzyński P, Kacprzak A, Domitrz W, et al. Migraine headache facilitators in a population of Polish women and their association with migraine occurrence - preliminary results. Neurol Neurochir Pol. 2019; 53(5): 377-383, doi: 10.5603/PJNNS.a2019.0044, indexed in Pubmed: 31592536.

17. World Health Organization. Global Health Estimates 2015: Disease Burden by Cause, Age, Sex, by Country and by Region, 2000-2015. Geneva, 2016. Available at: http://www.who.int/healthinfo/global_burden_disease/estimates/en/index2.html. Accessed October. ; 26: 2018.

18. Linde M, Gustavsson A, Stovner $L$, et al. The cost of headache disorders in Europe: the Eurolight project. Eur J Neurol. 2012; 19(5): 703-711, doi: 10.1111/j.1468-1331.2011.03612.x, indexed in Pubmed: 22136117.
19. Stewart WF, Lipton PR, Celentano DD, et al. Prevalence of migraine headache in United States. Relation to age, icome, race and other sociodemographic factors. JAMA. 1992; 267: 64-9.

20. Domitrz I, Lipa A, Rożniecki J, et al. Treatment and management of migraine in neurological ambulatory practice in Poland by indicating therapy with monoclonal anti-CGRP antibodies. Neurologia i Neurochirurgia Polska. 2020; 54(4): 337-343, doi: 10.5603/pjnns.a2020.0054.

21. Headache Classification Committee of the International Headache Society. Classification and diagnostic criteria for headache disorders, cranial neuralgias, and facial pain. Cephalalgia. 1988; 8: 1-96.

22. Headache Classification Committee of the International Headache Society, International Classification of Headache Disorders. Cephalalgia. 2004; 24(S1): 9-160.

23. Headache Classification Committee of the International Headache Society (IHS). The International Classification of Headache Disorders, 3rd edition (beta version). Cephalalgia. 2013; 33(9): 629-808, doi: 10.1177/0333102413485658, indexed in Pubmed: 23771276.

24. Prusiński A. Migrena w praktyce lekarza rodzinnego Świat Medycyny. 2003; 3(44): 23-28.

25. Linde $M$, Mellberg A, Dahlöf $C$. The natural course of migraine attacks. A prospective analysis of untreated attacks compared with attacks treated with a triptan. Cephalalgia. 2006; 26(6): 712-721, doi: 10.1111/j.1468-2982.2006.01097.x, indexed in Pubmed: 16686911.

26. Silberstein SD. Migraine symptoms: results of a survey of self-reported migraineurs. Headache. 1995; 35(7): 387-396, doi: 10.1111/j.15264610.1995.hed3507387.x, indexed in Pubmed: 7672955.

27. Marmura MJ, Silberstein SD, Schwedt TJ. The acute treatment of migraine in adults: the american headache society evidence assessment of migraine pharmacotherapies. Headache. 2015; 55(1): 3-20, doi: 10.1111/head.12499, indexed in Pubmed: 25600718.

28. Becker WJ. Acute Migraine Treatment in Adults. Headache. 2015; 55(6): 778-793, doi: 10.1111/head.12550, indexed in Pubmed: 25877672.

29. Diener HC, Bussone G, de Li, et al. Placebocontrolled comparison of effervescent acetylsalicylic acid, sumatriptan and ibuprofen in the treatment of migraine attacks. Cephalalgia. 2004; 24: 947-954.

30. Nebe J, Heier M, Diener HC. Low-dose ibuprofen in self-medication of mild to moderate headache: a comparison with acetylsalicylic acid and placebo. Cephalalgia. 1995; 15(6): 531-535, doi: 10.1046/j.1468-2982.1995.1506531.x, indexed in Pubmed: 8706118.

31. Dahlo" $f \mathrm{C}$, Bjo "rkman R. Diclofenac-K (50 and $100 \mathrm{mg}$ ) and placebo in the acute treatment of migraine. Cephalalgia. 1993; 13: 117-123.

32. Diener HC, Bussone G, de Li, et al. Placebocontrolled comparison of effervescent acetylsalicylic acid, sumatriptan and ibuprofen in the treatment of migraine attacks. Cephalalgia. 2004; 24: 947-954.

33. Ward N, Whitney C, Avery D, et al. The analgesic effects of caffeine in headache. Pain. 1991; 44(2): 151-155, doi: 10.1016/03043959(91)90129-I, indexed in Pubmed: 2052380.

34. Fiebich BL, Lieb K, Kammerer N, et al. Effects of caffeine and paracetamol alone or in combination with acetylsalicylic acid on prostaglandin $E(2)$ synthesis in rat microglial cells. Neuropharmacology. 2000; 39(11): 2205-2213, doi: 10.1016/s0028-3908(00)00045-9, indexed in Pubmed: 10963764.

35. Yǔcel A, Őzyalein S. Talu GK, Yúcel EC, Erdine S. Intarvenous administration of caffeine sodium benzoate for postura punctate headache. Rg Anesth Pain Med. 1999; 2: 51-4.

36. Dinner HC, Pfaffenrath V, Pageler L, et al. The fixed combination of acetylsalicylic acid, paracetamol and caffeine is more effective than single substances and dual combination fort the treatment of heada- 
che: a multicentre, randomized, double - blind, single - dose, placebo - controlled parallel group study. Cephalalgia. 2005; 25: 776-787.

37. Goldstein J, Silberstein S, Saper J, et al. Acetaminophen, Aspirin, and Caffeine Versus Sumatriptan Succinate in the Early Treatment of Migraine: Results From the ASSET trial. Headache: The Journal of Head and Face Pain. 2005; 45(8): 973-982, doi: 10.1111/j.1526$-4610.2005 .05177 . x$.

38. Bigal ME, Bordini CA, Tepper SJ, et al. Intravenous dipyrone in the acute treatment of migraine without aura and migraine with aura: a randomized, double blind, placebo controlled study. Headache. 2002; 42(9): 862-871, doi: 10.1046/j.1526-4610.2002.02204.x, indexed in Pubmed: 12390611.

39. W. Kozubski: Metamizole and hydrocortisone for the interruption of migraine attack - preliminary study. Headache Quarterly 3. ; 1992: 309.

40. Stępień A, Kozubski W. Ocena skuteczności leczenia napadu migreny acetylosalicylanem lizyny w połączeniu z chlorowodorkiem metoklopramidu. Pol. Merk. Lek. 2004; XVII. ; 102: 615-619.

41. Titus F, Escamilla C, Palmeira MG, et al. A Double-Blind Comparison of Lysine Acetylsalicylate plus Metoclopramide vs Ergotamine plus Caffeine in Migraine. Clinical Drug Investigation. 2001; 21(2): 87-94, doi: 10.2165/00044011-200121020-00001.

42. Friedman BW, Corbo J, Lipton RB, et al. A trial of metoclopramide vs sumatriptan for the emergency department treatment of migraines. Neurology. 2005; 64(3): 463-468, doi: 10.1212/01. WNL.0000150904.28131.DD, indexed in Pubmed: 15699376.

43. Láinez MJA, Galván J, Heras J, et al. Crossover, double-blind clinical trial comparing almotriptan and ergotamine plus caffeine for acute migraine therapy. Eur J Neurol. 2007; 14(3): 269-275, doi: 10.1111/j.1468-1331.2006.01594.x, indexed in Pubmed: 17355546.

44. Welch KM. Stroke and migraine-the spectrum of cause and effect. Funct Neurol. 2003; 18: 121-126.

45. Ferrari M. Migraine. The Lancet. 1998; 351(9108): 1043-1051, doi: 10.1016/s0140-6736(97)11370-8.

46. Ferrari $\mathrm{MD}$, Roon $\mathrm{KI}$, Lipton RB, et al. Oral triptans (serotonin $5-\mathrm{HT}(1 \mathrm{~B} / 1 \mathrm{D})$ agonists) in acute migraine treatment: a meta-analysis of 53 trials. Lancet. 2001; 358(9294): 1668-1675, doi: 10.1016/ S0140-6736(01)06711-3, indexed in Pubmed: 11728541.

47. Derry S, Moore R, McQuay H. Paracetamol (acetaminophen) with or without an antiemetic for acute migraine headaches in adults. Cochrane Database of Systematic Reviews. 2010, doi: 10.1002/14651858. cd008040.pub2.

48. Colman SS, Brod MI, Krishnamurthy A, et al. Treatment satisfaction, functional status, and health-related quality of life of migraine patients treated with almotriptan or sumatriptan. Clin Ther. 2001; 23(1): 127-145, doi: 10.1016/s0149-2918(01)80036-9, indexed in Pubmed: 11219473.

49. Pascual J, Cabarrocas X. Within-patient early versus delayed treatment of migraine attacks with almotriptan: the sooner the better. Headache. 2002; 42(1): 28-31, doi: 10.1046/j.1526-4610.2002.02010.x, indexed in Pubmed: 12005272.

50. Klapper J, Lucas C, Røsjø Ø, et al. ZODIAC study group. Benefits of treating highly disabled migraine patients with zolmitriptan while pain is mild. Cephalalgia. 2004; 24(11): 918-924, doi: 10.1111/j.1468-2982.2004.00735.x, indexed in Pubmed: 15482352.

51. Smith LA, Oldman AD, McQuay HJ, et al. Eletriptan for acute migraine. Cochrane Database Syst Rev. 2001(3): CD003224, doi: 10.1002/14651858.CD003224, indexed in Pubmed: 11687056.

52. Láinez M. Clinical benefits of early triptan therapy for migraine. Cephalalgia. 2004; 24 Suppl 2: 24-30, doi: 10.1111/j.1468-2982.2004.00895.x, indexed in Pubmed: 15595991.
53. Olesen J, Diener HC, Schoenen J, et al. No effect of eletriptan administration during the aura phase of migraine. Eur J Neurol. 2004; 11(10): 671-677, doi: 10.1111/j.1468-1331.2004.00914.x, indexed in Pubmed: 15469451.

54. Goadsby PJ, Zanchin G, Geraud G, et al. Early vs. non-early intervention in acute migraine-'Act when Mild (AwM)'. A double-blind, placebo-controlled trial of almotriptan. Cephalalgia. 2008; 28(4): 383-391, doi: 10.1111/j.1468-2982.2008.01546.x, indexed in Pubmed: 18294251.

55. Katsarava Z, Fritsche G, Muessig M, et al. Clinical features of withdrawal headache following overuse of triptans and other headache drugs. Neurology. 2001; 57: 1694-1698.

56. Ferrari M. How to assess and compare drugs in the management of migraine: success rates in terms of response and recurrence. Cephalalgia. 1999; 19 Suppl 23: 2-4; discussion 4, doi: 10.1177/0333102499019s2302, indexed in Pubmed: 10099848.

57. Ferrari MD, James MH, Bates D, et al. Oral sumatriptan: effect of a second dose, and incidence and treatment of headache recurrences. Cephalalgia. 1994; 14(5): 330-338, doi: 10.1046/j.1468-2982.1994.1405330.x, indexed in Pubmed: 7828190.

58. Hall GC, Brown MM, Mo J, et al. Triptans in migraine: the risks of stroke, cardiovascular disease, and death in practice. Neurology. 2004; 62(4): 563-568, doi: 10.1212/01.wnl.0000110312.36809.7f, indexed in Pubmed: 14981171.

59. Stark S, Spierings EL, McNeal S, et al. Naratriptan efficacy in migraineurs who respond poorly to oral sumatriptan. Headache. 2000; 40(7): 513-520, doi: 10.1046/j.1526-4610.2000.00082.x, indexed in Pubmed: 10940089.

60. Ferrari MD, Roon KI, Lipton RB, et al. Oral triptans (serotonin 5-HT1B/1D agonists) in acute migraine treatment: a meta-analysis of 53 trials. Lancet. 2001; 358: 1668-1675.

61. Dodick DW, Martin V. Triptans and CNS side effects: pharmacokinetic and metabolic mechanism. Cephalalgia. 2004; 24: 417-24.

62. Orlova Y, Rizzoli P, Loder E. Association of Coprescription of Triptan Antimigraine Drugs and Selective Serotonin Reuptake Inhibitor or Selective Norepinephrine Reuptake Inhibitor Antidepressants With Serotonin Syndrome. JAMA Neurol. 2018; 75(5): 566-572, doi: 10.1001/ jamaneurol.2017.5144, indexed in Pubmed: 29482205.

63. Tfelt-Hansen P. A reviev of evidence-based medicine and meta-analytic reviews in migraine. Cephalalgia. 2006; 26: 1265-1274.

64. Mathew N, Kailasam J, Meadors L, et al. Intravenous val proate sodium (depacon) aborts migraine rapidly: a premilinary report. Headache. 2000; 40: 720-723.

65. Leniger T, Pageler L, Stude P. Diener H-Ch, Limmorth V. Comparison of intravenous valproate with intravenous lysine - acetylsalicylic acid in acute migraine attacks. Headache. 2005; 45: 42-46.

66. Mathew NT, Kailasam J, Meadors L, et al. Intravenous valproate sodium (depacon) aborts migraine rapidly: a preliminary report. Headache. 2000; 40(9): 720-723, doi: 10.1046/j.1526-4610.2000.00125.x, indexed in Pubmed: 11091289.

67. Edwards KR, Norton J, Behnke M. Comparison of intravenous valproate versus intramuscular dihydroergotamine and metoclopramide for acute treatment of migraine headache. Headache. 2001; 41(10): 976-980, doi: 10.1046/j.1526-4610.2001.01191.x, indexed in Pubmed: 11903525.

68. Norton J. Use of intravenous valproate sodium in status migraine. Headache. 2000; 40(9): 755-757, doi: 10.1046/j.1526-4610.2000.00133.x, indexed in Pubmed: 11091297.

69. Bigal ME, Bordini CA, Tepper SJ, et al. Intravenous magnesium sulphate in the acute treatment of migraine without aura and mi- 
graine with aura. A randomized, double-blind, placebo-controlled study. Cephalalgia. 2002; 22(5): 345-353, doi: 10.1046/j.1468-2982.2002.00364.x, indexed in Pubmed: 12110110.

70. DA approves new treatment for patients with migraine [press release]. . https://www.fda.gov/news-events/press-announcements/ fda-approves-new-treatment-patients-migraine (October 11, 201).

71. Goadsby PJ. Primary headache disorders: Five new things. Neurol Clin Pract. 2019; 9(3): 233-240, doi: 10.1212/CPJ.0000000000000654, indexed in Pubmed: 31341711.

72. Oswald JC, Schuster NM. Lasmiditan for the treatment of acute migraine: a review and potential role in clinical practice. J Pain Res. 2018; 11: 2221-2227, doi: 10.2147/JPR.S152216, indexed in Pubmed: 30323656.

73. Edvinsson L, Haanes KA, Warfvinge K, et al. CGRP as the target of new migraine therapies - successful translation from bench to clinic. Nat Rev Neurol. 2018; 14(6): 338-350, doi: 10.1038/s41582-018-00031, indexed in Pubmed: 29691490.

74. Kuca B, Silberstein SD, Wietecha L, et al. COL MIG-301 Study Group. Lasmiditan is an effective acute treatment for migraine: A phase 3 randomized study. Neurology. 2018; 91(24): e2222-e2232, doi: 10.1212/WNL.0000000000006641, indexed in Pubmed: 30446595.

75. Goadsby PJ, Wietecha LA, Dennehy EB, et al. Phase 3 randomized, placebo-controlled, double-blind study of lasmiditan for acute treatment of migraine. Brain. 2019; 142(7): 1894-1904, doi: 10.1093/ brain/awz134, indexed in Pubmed: 31132795.

76. Croop, R, Goadsby, PJ, Lipton, RB, Efficacy, safety, and tolerability of rimegepant orally disintegrating tablet for the acute treatment of migraine: A randomised, phase 3, double-blind, placebo-controlled trial. Lancet. 2019; 394: 737-745.

77. Lipton RB, Manack A, Ricci JA, et al. Prevalence and burden of chronic migraine in adolescents: results of the chronic daily headache in adolescents study (C-dAS). Headache. 2011; 51(5): 693-706, doi: 10.1111/j.1526-4610.2011.01885.x, indexed in Pubmed: 21521206.

78. D'Amico D, Grazzi L, Usai S, et al. Disability and quality of life in headache: where we are now and where we are heading. Neurol Sci. 2013; 34 Suppl 1: S1-S5, doi: 10.1007/s10072-013-1378-9, indexed in Pubmed: 23695035.

79. Stokes M, Becker WJ, Lipton RB, et al. Cost of health care among patients with chronic and episodic migraine in Canada and the USA: results from the International Burden of Migraine Study (IBMS). Headache. 2011; 51(7): 1058-1077, doi: 10.1111/j.1526-4610.2011.01945.x, indexed in Pubmed: 21762134.

80. Bigal ME, Lipton RB. What predicts the change from episodic to chronic migraine? Curr Opin Neurol. 2009; 22(3): 269-276, doi: 10.1097/ WC0.0b013e32832b2387, indexed in Pubmed: 19381087.

81. Couch JR. Amitryptyline in the prophylactic treatment of migraine and chronic daily headache. Headache. 2011; 51: 33-51.

82. Diener HC, Matias-Guiu J, Hartung E, et al. Efficacy and tolerability in migraine prophylaxis of flunarizine in reduced doses: a comparison with propranolol 160 mg daily. Cephalalgia. 2002; 22(3): 209-221, doi: 10.1046/ j.1468-2982.2002.t01-1-00309.x, indexed in Pubmed: 12047461.

83. Freitag FG, Collins SD, Carlson HA, et al. Depakote ER Migraine Study Group. A randomized trial of divalproex sodium extended-release tablets in migraine prophylaxis. Neurology. 2002; 58(11): 1652-1659, doi: 10.1212/wnl.58.11.1652, indexed in Pubmed: 12058094.

84. Brandes JL, Saper JR, Diamond M, et al. MIGR-002 Study Group. Topiramate for migraine prevention: a randomized controlled trial. JAMA.
2004; 291(8): 965-973, doi: 10.1001/jama.291.8.965, indexed in Pubmed: 14982912.

85. Diener HC, Tfelt-Hansen P, Dahlöf C, et al. MIGR-003 Study Group. Topiramate in migraine prophylaxis-results from a placebo-controlled trial with propranolol as an active control. J Neurol. 2004; 251(8): 943-950, doi: 10.1007/s00415-004-0464-6, indexed in Pubmed: 15316798.

86. Siniatchkin M, Andrasik F, Kropp P, et al. Central mechanisms of controlled-release metoprolol in migraine: a double-blind, placebo-controlled study. Cephalalgia. 2007; 27(9): 1024-1032, doi: 10.1111/j.1468-2982.2007.01377.x, indexed in Pubmed: 17680819.

87. Linde K, Rossnagel K. Propranolol for migraine prophylaxis. Cochrane Database Syst Rev. 2004(2): CD003225, doi: 10.1002/14651858. CD003225.pub2, indexed in Pubmed: 15106196.

88. Messerli FH, Bangalore S, Julius S. Risk/benefit assessment of beta-blockers and diuretics precludes their use for first-line therapy in hypertension. Circulation. 2008; 117(20): 2706-15; discussion 2715, doi: 10.1161/CIRCULATIONAHA.107.695007, indexed in Pubmed: 18490538.

89. Maggioni F, Ruffatti S, Dainese F, et al. Weight variations in the prophylactic therapy of primary headaches: 6-month follow-up. J Headache Pain. 2005; 6(4): 322-324, doi: 10.1007/s10194-005-0221-y, indexed in Pubmed: 16362700.

90. Product Information: HEMANGEOL(TM) Oral Solution, Propranolol HCl Oral Solution. Pierre Fabre Pharmaceuticals, Inc. (per FDA), Parsippany, NJ. ; 2014.

91. Cupini LM, Troisi E, Placidi F, et al. Does the antimigraine action of flunarizine involve the dopaminergic system? A clinical-neuroendocrinological study. Cephalalgia. 1999; 19(1): 27-31, doi: 10.1111/j.1468-2982.1999.1901027.x, indexed in Pubmed: 10099857.

92. Krusz JC, Scott V. Topiramate in the treatment of chronic migraine and other headaches. Headache. 1999; 39: 363-369.

93. Von Seggern RL, Mannix LK, Adelman JU. Efficacy of topiramate in migraine prophylaxis: a retrospective chart analysis. Headache. 2002; 42(8): 804-809, doi: 10.1046/j.1526-4610.2002.02184.x, indexed in Pubmed: 12390645.

94. Akerman S, Goadsby PJ. Topiramate inhibits cortical spreading depression in rat and cat: a possible contribution to its preventive effect in migraine. Cephalalgia. 2004; 24: 783-784.

95. Diener HC, Bussone G, Van Oene JC, et al. TOPMAT-MIG-201(TOP-CHROME) Study Group. Topiramate reduces headache days in chronic migraine: a randomized, double-blind, placebo-controlled study. Cephalalgia. 2007; 27(7): 814-823, doi: 10.1111/j.1468-2982.2007.01326.x, indexed in Pubmed: 17441971.

96. Taylor FR. Weight change associated with the use of migraine-preventive medications. Clin Ther. 2008; 30(6): 1069-1080, doi: 10.1016/j. clinthera.2008.06.005, indexed in Pubmed: 18640463.

97. Pascual J, Rivas MT, Leira R. Testing the combination beta-blocker plus topiramate in refractory migraine. Acta Neurol Scand. 2007; 115(2): 81-83, doi: 10.1111/j.1600-0404.2006.00772.x, indexed in Pubmed: 17212609.

98. Bhoi SK, Kalita J, Misra UK. Is 6 months of migraine prophylaxis adequate? Neurol Res. 2013; 35(10): 1009-1014, doi: 10.1179/1743132813Y.0000000244, indexed in Pubmed: 23890081.

99. Brandes JL, Saper JR, Diamond M, et al. MIGR-002 Study Group. Topiramate for migraine prevention: a randomized controlled trial. JAMA. 2004; 291(8): 965-973, doi: 10.1001/jama.291.8.965, indexed in Pubmed: 14982912. 
100. Silberstein SD, Neto W, Schmitt J, et al. for the MIGR-001 Study Group. Topiramate in migraine prevention: Results of a large controlled trial. Arch Neurol. 2004; 61: 490-495.

101. Klapper J. Divalproex sodium in migraine prophylaxis: a dose-controlled study. Cephalalgia. 1997; 17(2): 103-108, doi: 10.1046/j.1468-2982.1997.1702103.x, indexed in Pubmed: 9137847.

102. FDA Drug Safety Communication. Children born to mothers who took valproate products while pregnant may have impaired cognitive development. Available at: https://www.fda.gov/Drugs/DrugSafety/ ucm261543.htm. Accessed October. ; 26: 2018.

103. Product Information: Depakote Oral Tablets, Divalproex Sodium Oral Tablets. AbbVie Inc. (per FDA), North Chicago, IL. ; 2015.

104. Dodick DW, Freitag F, Banks J, et al. CAPSS-277 Investigator Group. Topiramate versus amitriptyline in migraine prevention: a 26-week, multicenter, randomized, double-blind, double-dummy, parallel-group noninferiority trial in adult migraineurs. Clin Ther. 2009; 31(3): 542-559, doi: 10.1016/j.clinthera.2009.03.020, indexed in Pubmed: 19393844

105. Bet PM, Hugtenburg JG, Penninx BW, et al. Side effects of antidepressants during long-term use in a naturalistic setting. Eur Neuropsychopharmacol. 2013; 23(11): 1443-1451, doi: 10.1016/j.euroneuro.2013.05.001, indexed in Pubmed: 23726508.

106. Fanoe S, Kristensen D, Fink-Jensen A, et al. Risk of arrhythmia induced by psychotropic medications: a proposal for clinical management. Eur Heart J. 2014; 35(20): 1306-1315, doi: 10.1093/ eurheartj/ehu100, indexed in Pubmed: 24644307.

107. Mathew NT, Bendtsen L. Prophylactic pharmacotheraphy of tension-type headache. W Olesen J, Tfelt-Hansen P. The Headache, 2 wydanie, Rozdz. 88, Philadelphia; Lippioncott, Williams \& Wilkins. ; 2000: 667-673.

108. Bryson H, Wilde M. Amitriptyline. Drugs \& Aging. 1996; 8(6): 459476, doi: 10.2165/00002512-199608060-00008.

109. Becker WJ. Evidence based migraine prophylactic drug therapy. Can J Neurol Sci. 1999; 26 Suppl 3: S27-S32, doi: 10.1017/ s0317167100000160, indexed in Pubmed: 10563230.

110. Diener HC, Dodick DW, Aurora SK, et al. PREEMPT 2 Chronic Migraine Study Group. OnabotulinumtoxinA for treatment of chronic migraine: results from the double-blind, randomized, placebo-controlled phase of the PREEMPT 2 trial. Cephalalgia. 2010; 30(7): 804-814, doi: 10.1177/0333102410364677, indexed in Pubmed: 20647171.

111. Negro A, Curto M, Lionetto L, et al. OnabotulinumtoxinA $155 \mathrm{U}$ in medication overuse headache: a two years prospective study. Springerplus. 2015; 4: 826, doi: 10.1186/s40064-015-1636-9, indexed in Pubmed: 26753113.

112. Cernuda-Morollón E, Ramón C, Larrosa D, et al. Long-term experience with onabotulinumtoxinA in the treatment of chronic migraine: What happens after one year? Cephalalgia. 2015; 35(10): 864-868, doi: 10.1177/0333102414561873, indexed in Pubmed: 25431141.

113. Rothrock JF, Andress-Rothrock D, Michael A. Can botox be stopped? Discontinuing onabotulinumtoxin a therapy following remission in infrequent episodic migraine. Headache. 2016; 56: 30.

114. VanderPluym J, Evans RW, Starling AJ. Long-Term Use and Safety of Migraine Preventive Medications. Headache. 2016; 56(8): 13351343, doi: 10.1111/head.12891, indexed in Pubmed: 27477594.

115. Simpson DM, Hallett M, Ashman EJ, et al. Practice guideline update summary: Botulinum neurotoxin for the treatment of blepharospasm, cervical dystonia, adult spasticity, and headache: Report of the Guideline Development Subcommittee of the American Academy of Neurology. Neurology. 2016; 86(19): 1818-1826, doi: 10.1212/ WNL.0000000000002560, indexed in Pubmed: 27164716.

116. Sun H, Dodick DW, Silberstein S, et al. Safety and efficacy of AMG 334 for prevention of episodic migraine: a randomised, double-blind, placebo-controlled, phase 2 trial. Lancet Neurol. 2016; 15(4): 382390, doi: 10.1016/S1474-4422(16)00019-3, indexed in Pubmed: 26879279.

117. Silberstein SD, Dodick DW, Bigal ME, et al. Fremanezumab for the Preventive Treatment of Chronic Migraine. N Engl J Med. 2017; 377(22): 2113-2122, doi: 10.1056/NEJMoa1709038, indexed in Pubmed: 29171818.

118. Skljarevski V, Oakes TM, Zhang Qi, et al. Effect of Different Doses of Galcanezumab vs Placebo for Episodic Migraine Prevention: A Randomized Clinical Trial. JAMA Neurol. 2018; 75(2): 187-193, doi: 10.1001/jamaneurol.2017.3859, indexed in Pubmed: 29255900.

119. Goldstein ED, Badi MK, Meschia JF. Treating chronic migraine in CADASIL with calcitonin gene-related peptide receptor antagonism. Neurol Clin Pract. 2019; 9(3): 277-278, doi: 10.1212/ CPJ.0000000000000651, indexed in Pubmed: 31341718.

120. AHS Position Steatment on Integrating New Migraine Treatments Into Clinical Practice. Headache. 2019; 59: 1-18.

121. Sacco European Headache Federation guideline on the use of monoclonal antibodies acting on the calcitonin gene related peptide or its receptor for migraine prevention. J Headache Pain. 2019; 20(1): 6.

122. Marmura MJ, Silberstein SD, Schwedt TJ. The acute treatment of migraine in adults: the american headache society evidence assessment of migraine pharmacotherapies. Headache. 2015; 55(1) 3-20, doi: 10.1111/head.12499, indexed in Pubmed: 25600718.

123. Silberstein S, Merriam G. Sex hormones and headache 1999 (menstrual migraine). Neurology. 1999; 53(4 Suppl 1): S3-13, indexed in Pubmed: 10487507.

124. Mattsson P. Hormonal factors in migraine: a population based study of women aged 40-74 years. Headache. 2003; 43: 27.

125. Angst J, Sellaro R, Merikangas KR, et al. The epidemiology of perimenstrual psychological symptoms. Acta Psychiatr Scand. 2001; 104(2): 110-116, doi: 10.1034/j.1600-0447.2001.00412.x, indexed in Pubmed: 11473504.

126. Solbach P, Sargent J, Coyne L. Menstrual migraine headache; results of a controlled, experimental, outcome study of nondrug treatments. Headache. 1984; 24: 75-78.

127. MacGregor EA, Chia H, Vohrah RC, et al. Migraine and menstruation: a pilot study. Cephalalgia. 1990; 10(6): 305-310, doi: 10.1046/j.1468-2982.1990.1006305.x, indexed in Pubmed: 2289231.

128. Couturier EGM, Bomhof MAM. Knuistingh Neven A, van Duijn NI. Menstrual migraine in a representative Dutch population sample: prevalence, disability and treatment. Cephalalgia. 2003; 23: 302308.

129. Granella F, Sances G, Pucci E, et al. Migraine with aura and reproductive life events: a case controlled study. Cephalalgia. 2000; 20(8): 701-707.

130. Newman L, Mannix LK, Landy S, et al. Naratriptan as Short-Term Prophylaxis of Menstrually Associated Migraine: A Randomized, Double-Blind, Placebo-Controlled Study. Headache: The Journal of Head and Face Pain. 2001; 41(3): 248-256, doi: 10.1046/j.1526$-4610.2001 .111006248 . x$.

131. Silberstein SD, Elkind AH, Schreiber C, et al. A randomized trial of frovatriptan for the intermittent prevention of menstrual mi- 
graine. Neurology. 2004; 63(2): 261-269, doi: 10.1212/01. wnl.0000134620.30129.d6, indexed in Pubmed: 15277618.

132. Newman L, Mannix LK, Landy S, et al. Naratriptan as Short-Term Prophylaxis of Menstrually Associated Migraine: A Randomized, Double-Blind, Placebo-Controlled Study. Headache: The Journal of Head and Face Pain. 2001; 41(3): 248-256, doi: 10.1046/j.1526$-4610.2001 .111006248 . x$.

133. Pradalier A, Vincent D, Beaulieu PH, et al. Launay J-M. Correlation between estradiol plasma level and therapeutic effect on menstrual migraine. In: Proceedings of the 10th Migraine Trust Symposium. London. ; 1994: 129-132.

134. Ephross SA, Sinclair SM. Final results from the 16-year sumatrip$\tan$, naratriptan, and treximet pregnancy registry. Headache. 2014; 54(7): 1158-1172, doi: 10.1111/head.12375, indexed in Pubmed: 24805878.

135. Brainin M, Barnes M, Baron JC, et al. Guideline Standards Subcommittee of the EFNS Scientific Committee. Guidance for the preparation of neurological management guidelines by EFNS scientific task forces-revised recommendations 2004. Eur J Neurol. 2004; 11(9): 577-581, doi: 10.1111/j.1468-1331.2004.00867.x, indexed in Pubmed: 15379736.

136. Silberstein S, Young WB, Mendizabal JE, et al. Efficacy of intramuscular droperidol for migraine treatment: a dose-response study. Cephalalgia 2001b. ; 21: 271-2.

137. Tanen DA, Miller S, French T, et al. Intravenous sodium valproate versus prochlorperazine for the emergency department treatment of acute migraine headaches: a prospective, randomized, double-blind trial. Ann Emerg Med. 2003; 41(6): 847-853, doi: 10.1067/ mem.2003.195, indexed in Pubmed: 12764341.

138. Kabbouche M, Vockell AL, LeCates S, et al. Tolerability and Effectiveness of Prochlorperazine for Intractable Migraine in Children. Pediatrics. 2001; 107(4): e62-e62, doi: 10.1542/peds.107.4.e62.

139. Maizels $M$. Health resource utilization of the emergency department headache "Repeater" Headache. 2002; 42: 747-753.
140. Friedman BW, Corbo J, Lipton RB, et al. A trial of metoclopramide vs sumatriptan for the emergency department treatment of migraines. Neurology. 2005; 64(3): 463-468, doi: 10.1212/01. WNL.0000150904.28131.DD, indexed in Pubmed: 15699376.

141. Long L, Ernst E, Ernst E. Homeopathic prophylaxis of headaches and migraine? A systematic review. J Pain Symptom Manage. 1999; 18(5): 353-357, doi: 10.1016/s0885-3924(99)00095-0, indexed in Pubmed: 10584459.

142. Ulusoy EK, Bolattürk ÖF. The effect of greater occipital nerve blockade on the quality of life, disability and comorbid depression, anxiety, and sleep disturbance in patients with chronic migraine. Neurol Sci. 2020; 41(7): 1829-1835, doi: 10.1007/s10072-020-04286-9, indexed in Pubmed: 32056056.

143. Ashkenazi A, Blumenfeld A, Napchan U, et al. Interventional Procedures Special Interest Section of the American. Peripheral nerve blocks and trigger point injections in headache management - a systematic review and suggestions for future research. Headache. 2010; 50(6): 943-952, doi: 10.1111/j.1526-4610.2010.01675.x, indexed in Pubmed: 20487039.

144. Riederer F, Penning S, Schoenen J. Transcutaneous Supraorbital Nerve Stimulation (t-SNS) with the Cefaly Device for Migraine Prevention: A Review of the Available Data. Pain Ther. 2015 [Epub ahead of print], doi: 10.1007/s40122-015-0039-5, indexed in Pubmed: 26467451.

145. Starling AJ, Tepper SJ, Marmura MJ, et al. A multicenter, prospective, single arm, open label, observational study of sTMS for migraine prevention (ESPOUSE Study). Cephalalgia. 2018; 38(6): 1038-1048, doi: 10.1177/0333102418762525, indexed in Pubmed: 29504483.

146. Chou DE, Gross GJ, Casadei CH, et al. External Trigeminal Nerve Stimulation for the Acute Treatment of Migraine: Open-Label Trial on Safety and Efficacy. Neuromodulation. 2017; 20(7): 678-683, doi: 10.1111/ner.12623, indexed in Pubmed: 28580703.

147. Varkey E, Cider A, Carlsson J, et al. Exercise as migraine prophylaxis: a randomized study using relaxation and topiramate as controls. Cephalalgia. 2011; 31(14): 1428-1438, doi: 10.1177/0333102411419681, indexed in Pubmed: 21890526. 